\title{
Satellite-Based Human Settlement Datasets Inadequately De- tect Refugee Settlements: A Critical Assessment of Area, Accu- racy, and Agreement at Thirty Refugee Settlements in Uganda
}

\author{
Jamon Van Den Hoek ${ }^{1, *}$ and Hannah K. Friedrich ${ }^{2}$ \\ 1 Geography Program, College of Earth, Ocean, and Atmospheric Sciences, Oregon State University; \\ jamon.vandenhoek@oregonstate.edu \\ 2 Geography Program, College of Earth, Ocean, and Atmospheric Sciences, Oregon State University; frie- \\ drih@oregonstate.edu \\ * Correspondence: jamon.vandenhoek@oregonstate.edu
}

\begin{abstract}
Satellite-based broad-scale (i.e., global and continental) human settlement data offer foundational information for diverse applications spanning climate hazard mitigation, sustainable development monitoring, spatial epidemiology, and demographic modeling. While many human settlement products report exceptional detection accuracies above $85 \%$, there is a substantial blind spot in that product validation is typically centered on large urban areas rather than rural, small-scale settlements that are home to 3.4 billion people. In this study, we make use of a data-rich collection of 30 refugee settlements in Uganda to produce a targeted assessment of small-scale settlement detection by four broad-scale human settlement products: Global Human Settlements Built-Up Sentinel-2 (GHS-BUILT-S2), World Settlement Footprint (WSF), High Resolution Settlement Layer (HRSL), and Geo-Referenced Infrastructure and Demographic Data for Development (GRID3). We measured each product's areal coverage within refugee settlements, assessed product detection accuracies in comparison to an independent dataset of 317,416 refugee settlement building footprints, and examined agreement between products. For refugee settlements established before 2016, the human settlement products had a low median F1-Score (F1) of 0.24, a high median false alarm rate of 0.59 , and tended to only agree at locations of highest building density. Individually, WSF entirely overlooked 8 of the 30 study refugee settlements (median F1=0.17); GHS-BUILT-S2 underestimated the building footprint area by a median $50 \%$ ( $F 1=0.15)$; GRID3 overestimated the building footprint area by a median $280 \%$ ( $F 1=0.38)$; and HRSL underestimated the median area by $7 \%(F 1=0.34)$. All products suffer from low detection accuracy and high false alarm rates, but GRID3 and HRSL, based on 0.5 meter resolution imagery, offer better detection accuracy than GHS-BUILT S2 and WSF, which are based on 10-30 meter resolution imagery. These results show that human settlement products have far to go in providing an accurate depiction of small-scale refugee settlements and would benefit from incorporating refugee settlements in training and validation of broad-scale human settlement detection.
\end{abstract}

Keywords: informal settlements; population; displacement; GHS; WSF; HRSL; GRID3; sub-Saharan Africa

\section{Introduction}

Broad-scale (i.e., global and continental) satellite-driven human settlement products including the Global Human Settlement Layer (GHSL; [1,2]), the World Settlement Footprint (WSF; [3]), the High Resolution Settlement Layer (HRSL; [4]), and Geo-Referenced Infrastructure and Demographic Data for Development (GRID3; [5]) attempt to capture the presence and extent of populated built-up regions across an array of urban and rural geographies [6]. These products have broadened our foundational awareness of where humans live and work [7-9] and made important contributions to population modeling 
[10-14], development monitoring [8,15-17], and climate hazard mitigation [18-21]. Much human settlement mapping research to date has focused on improving measures of urbanization $[7,8,22,23]$ but there has been very little formal examination of the inclusion of small-scale settlements in broad-scale human settlement products (with exceptions [24,25]), despite approximately 3.4 billion people living in rural, small-scale settlements, including over half of Africa's population [26].

Refugee settlements managed by the United Nations High Commissioner for Refugees (UNHCR) offer an ideal test case for gauging small-scale settlement detection by satellite-based human settlement datasets. Refugee settlements are located in 132 countries and home to approximately one-third of the 21 million refugees under UNHCR protection as of late 2020 who have been forcibly displaced across national borders due to violence, persecution, or intimidation [27]. The average length of stay in a refugee settlement was 10 years as of 2015 [28] though many settlements become intergenerational homes through a "protracted refugee scenario" in which refugee populations greater than twenty-five thousand people are displaced for greater than five years [29]. The location, setting, and timing of refugee settlements are broadly documented with openly accessible geospatial data on building footprints, settlement boundaries, as well as ancillary information on settlement population, refugee arrival, and duration of habitation, much of which has been collected in support of rapid or prolonged humanitarian support [30].

The diversity of spatio-temporal data on refugee settlement is beneficial for a targeted assessment of refugee settlement inclusion in broad-scale human settlement products, yet there has never been a formal assessment of the detection of refugee settlements. There are, by contrast, many examples of individual refugee settlements being analyzed using high or moderate resolution (e.g., Sentinel and Landsat) satellite imagery or derived products to estimate settlement area [31,32], record dwellings [33-37], model refugee settlement population [38], guide the delivery of aid and relief $[39,40]$, assess environmental conditions [41-44], map land cover/use change [45-47], and quantify economic development [48]. However, there is a large gap between tailored local scale mapping and systematic global scale mapping of human settlements, and several characteristics of refugee settlements likely challenge broad-scale detection. First, many refugee settlements consist of small-scale dwellings and structures that are diffusely distributed and interspersed with vegetation or bare earth $[41,46,49]$, leading to mixed pixels in Sentinel-1 and Sentinel2, Landsat, and other moderate resolution satellite imagery. Second, building materials used in refugee settlements may include plastic tarp, wood fiber, thatching, and mud, which have distinct spectral signatures from typical materials used outside of humanitarian settings [50] and may also offer less spectral separability from the immediate surroundings. Third, refugee settlements tend to be rapidly built and settled, sometimes only over the course of weeks to months, but can also be inhabited for generations on end. To capture this evolution of the refugee settlement, a low latency, continual monitoring approach would be required $[39,40]$.

The goal of this study is to assess how well broad-scale satellite image-based human settlement products capture individual refugee settlements. With a case study of $30 \mathrm{UN}$ HCR refugee settlements in Uganda that were settled between 1960 and 2018, we use four human settlement datasets -- the Global Human Settlement Layer from Sentinel-2 (GHSBUILT-S2), the World Settlement Footprint (WSF), the High Resolution Settlement Layer (HRSL) and GRID3 (Geo-Referenced Infrastructure and Demographic Data for Development), two building footprint datasets (OpenStreetMap and Microsoft), and georeferenced refugee boundary data to address three specific objectives. We measure the coverage of satellite-derived human settlement products within each refugee settlement, quantify building footprint detection accuracy, and characterize multi-product agreement (i.e., regions of mutual detection) between settlement datasets. For each objective, we summarize results across the 30 refugee settlements as well as at the settlement-level and offer qualitative and quantitative interpretations of various settlement and dataset-specific factors affecting our findings. This study offers the first systematic assessment of refugee settlement detection in broad-scale remote sensing-derived human settlement products 
with broader relevance for small-scale settlement mapping, helps bridge the divide between localized humanitarian and broad-scale human settlement monitoring efforts, and contributes to an ongoing discussion of improving inclusive representation of refugees in geospatial Big Data (e.g., [51,52]).

\section{Study Area}

As of writing, Uganda has the third largest refugee population in the world with 1.4 million refugees (nearly 3\% of Uganda's total population) under UNHCR protection [53]. Uganda's earliest refugees settled in the 1960s, but the population increased almost tenfold between 2012-2017 with the arrival of refugees from South Sudan, the Democratic Republic of the Congo (DRC), and Burundi (Fig. 1). Given that the same conflicts that forced refugees to leave their home countries in the first place are often ongoing, many refugees in Uganda do not intend to return to their home country and are likely to remain settled in Uganda for years to come [54]. Approximately 94\% of Uganda's refugees live in 30 UNHCR-managed settlements in the Northern and Western Regions of the country (Fig. 2), and the remaining $6 \%$ of Uganda's refugee population lives in the capital city of Kampala [55]. The abundance of refugee settlements, diversity of settlement morphologies and density, availability of settlement boundary and building footprint data -- as described below -- make Uganda an ideal case study to evaluate the detection of refugee settlements by broad-scale human settlement products.

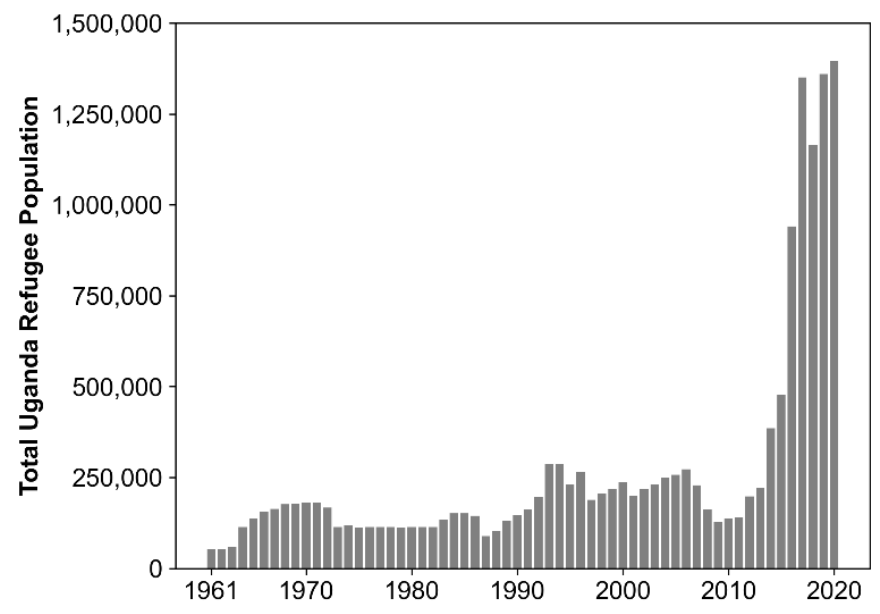

Figure 1. Total Refugee Population in Uganda from 1961-2020 based on UNHCR data at www.unhcr.org/refugee-statistics/download/?url=C06z. 

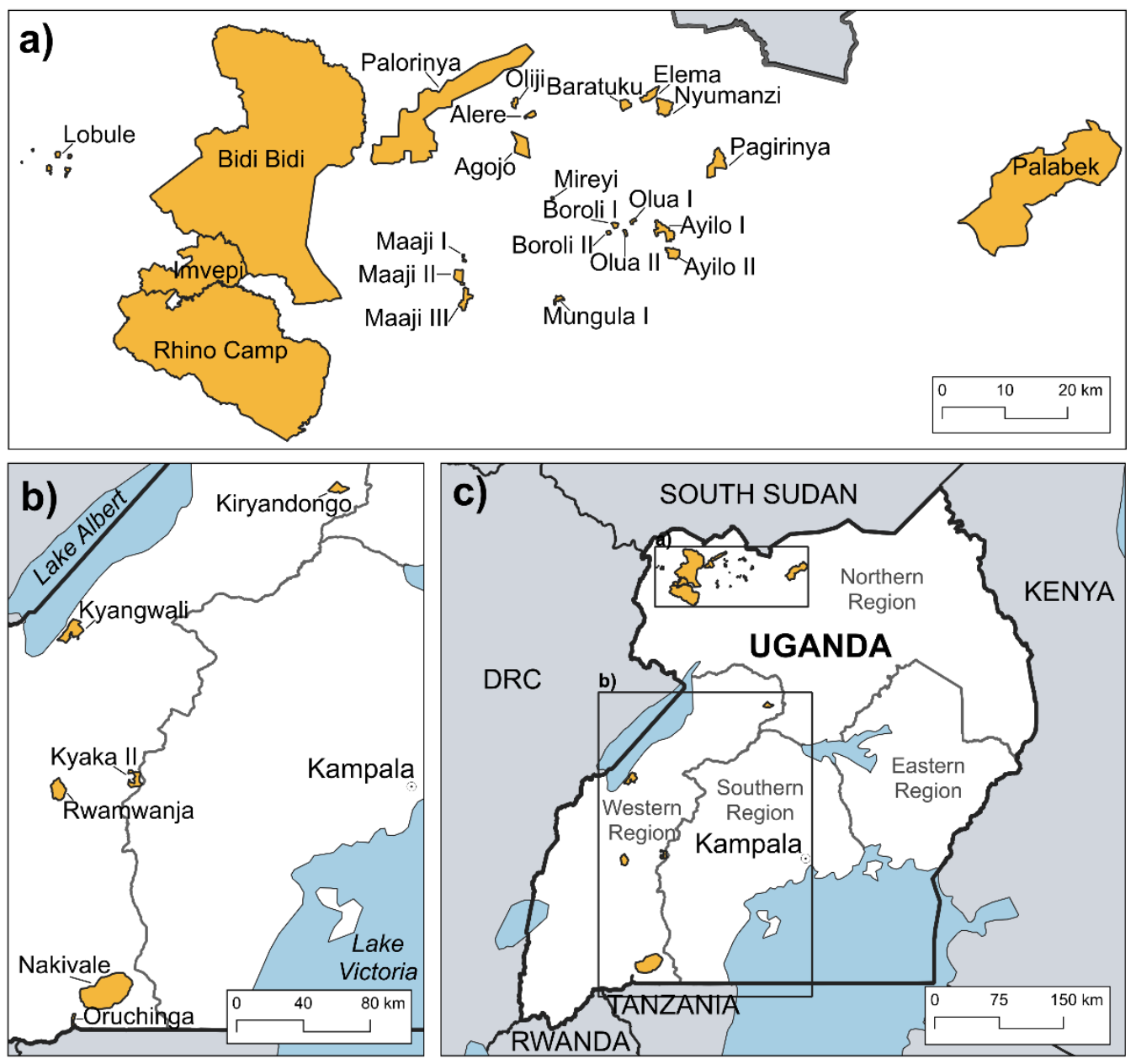

Figure 2. Thirty UNHCR-managed study refugee settlements in a) Northern and b) Western regions of c) Uganda. DRC: Democratic Republic of the Congo.

The 30 study refugee settlements have a median area of $4 \mathrm{~km}^{2}$ but range from $0.2 \mathrm{~km}^{2}$ (Mireyi) to $790 \mathrm{~km}^{2}$ (Bidi Bidi) in total area. Refugee settlements have a median population of 16,782 people (mean: 47,619; standard deviation: 58,093) as of September 2020 (Table 1). Settlement layouts adhere to predefined UNHCR settlement planning protocols [56], but are uniquely designed to fit site-specific considerations and vary from a grid-like organization of dwellings and other structures delineated by roadways to clustered agglomerations of dwellings. Settlements are broadly self-contained with housing, water and latrine infrastructure (WASH), markets, financial services, and educational and healthcare facilities on site, as well as buildings for refugee response (i.e., processing and registering arriving refugees) and administration (i.e., settlement management, aid provision, inter-sector coordination etc.). Each family is allocated a $30 \mathrm{~m}$ by $30 \mathrm{~m}$ plot for housing and agricultural cultivation, and individual dwellings tend to be small (median area of $25 \mathrm{~m}^{2}$ ). Typical materials used for dwellings at the time of refugee arrival are plastic tents, tarps, or grass thatching, which may be replaced with more durable building materials over time potentially including brick and tin roofing [43].

Table 1. Characteristics of 30 study refugee settlements in Uganda. Establishment year based on UNHCR Settlement Factsheets. Primary country of origin and population data (as of September 2020) are from https://data2.unhcr.org/en/documents/details/79424. Settlement boundary areas are from https://data2.unhcr.org/en/documents/details/74116, described below. Building footprint areas are based on 10 meter resolution OSM-MS building footprint data, described below. DRC: Democratic Republic of the Congo.

\begin{tabular}{|c|c|c|c|c|c|}
\hline $\begin{array}{c}\text { Settlement } \\
\text { Name }\end{array}$ & $\begin{array}{c}\text { Year Estab- } \\
\text { lished }\end{array}$ & $\begin{array}{c}\text { Primary Coun- } \\
\text { try of Origin }\end{array}$ & Population & $\begin{array}{c}\text { Settlement Bound- } \\
\left.\text { ary Area } \mathbf{( k m}^{\mathbf{2}}\right)\end{array}$ & $\begin{array}{c}\text { Building Foot- } \\
\text { print Area } \\
\left(\mathbf{k m}^{2}\right)\end{array}$ \\
\hline Agojo & 2016 & South Sudan & 7,167 & 6.7 & 0.23 \\
\hline
\end{tabular}




\begin{tabular}{|c|c|c|c|c|c|}
\hline Alere & 2013 & South Sudan & 6,882 & 1.2 & 0.16 \\
\hline Ayilo I & 2015 & South Sudan & 26,051 & 4.9 & 1.54 \\
\hline Ayilo II & 2014 & South Sudan & 14,623 & 2.9 & 0.84 \\
\hline Baratuku & 2013 & South Sudan & 7,049 & 2.2 & 0.26 \\
\hline Bidi Bidi & 2016 & South Sudan & 232,726 & 790.6 & 14.93 \\
\hline Boroli I & 2014 & South Sudan & 10,098 & 0.7 & 0.26 \\
\hline Boroli II & 2015 & South Sudan & 5,138 & 0.4 & 0.17 \\
\hline Elema & 1992 & South Sudan & 991 & 3.2 & 0.04 \\
\hline Imvepi & 2017 & South Sudan & 69,192 & 96.7 & 2.24 \\
\hline Kiryandongo & 2014 & South Sudan & 67,704 & 41.7 & 1.70 \\
\hline Kyaka II & 2017 & DRC & 123,831 & 45.1 & 1.64 \\
\hline Kyangwali & 1960 & DRC & 123,025 & 96.3 & 2.08 \\
\hline Lobule & 2013 & DRC & 5,547 & 2.2 & 0.13 \\
\hline Maaji I & 1997 & South Sudan & 548 & 0.3 & 0.04 \\
\hline Maaji II & 2015 & South Sudan & 17,518 & 3.3 & 0.68 \\
\hline Maaji III & 2015 & South Sudan & 16,046 & 2.6 & 0.52 \\
\hline Mireyi & 1994 & South Sudan & 7,067 & 0.2 & 0.11 \\
\hline Mungula I & 1996 & South Sudan & 5,028 & 1.1 & 0.28 \\
\hline Nakivale & 2015 & DRC & 133,192 & 458.2 & 8.56 \\
\hline Nyumanzi & 2014 & South Sudan & 40,877 & 5.2 & 1.51 \\
\hline Oliji & 2013 & South Sudan & 1,420 & 1.1 & 0.09 \\
\hline Olua I & 2012 & South Sudan & 5,359 & 0.5 & 0.12 \\
\hline Olua II & 2012 & South Sudan & 4,241 & 0.4 & 0.10 \\
\hline Oruchinga & 1961 & DRC & 7,909 & 10.7 & 0.44 \\
\hline Pagirinya & 2016 & South Sudan & 36,784 & 7.2 & 1.43 \\
\hline Palabek & 2017 & South Sudan & 53,806 & 207.1 & 2.56 \\
\hline Palorinya & 2016 & South Sudan & 122,805 & 114.7 & 5.37 \\
\hline Rhino Camp & 1980 & South Sudan & 121,171 & 490.3 & 9.79 \\
\hline Rwamwanja & 2012 & DRC & 72,997 & 79.2 & 3.66 \\
\hline
\end{tabular}

\section{Materials and Data}

\subsection{UNHCR Refugee Settlement Boundary Data}

Refugee settlement boundaries (Fig. 3) demarcate land allocated to refugee settlements for planning and land management purposes and were established by UNHCR in agreement with the Government of Uganda. Several of the larger settlements (Bidi Bidi, Rhino Camp, and Imvepi) include sub-settlement boundaries (i.e., zones, villages, blocks) that delineate specific regions of refugee presence from non-refugee populations within the larger settlement boundary [56]. As a result, it is common for refugee populations to only occupy a portion of the area demarcated by the UNHCR refugee settlement boundary. The boundary does not represent an absolute barrier to refugee land use as structures, transportation infrastructure, and agricultural plots are commonly established alongside or beyond the boundary. UNHCR refugee settlement boundaries are available at https://data2.unhcr.org/en/documents/details/74116. 

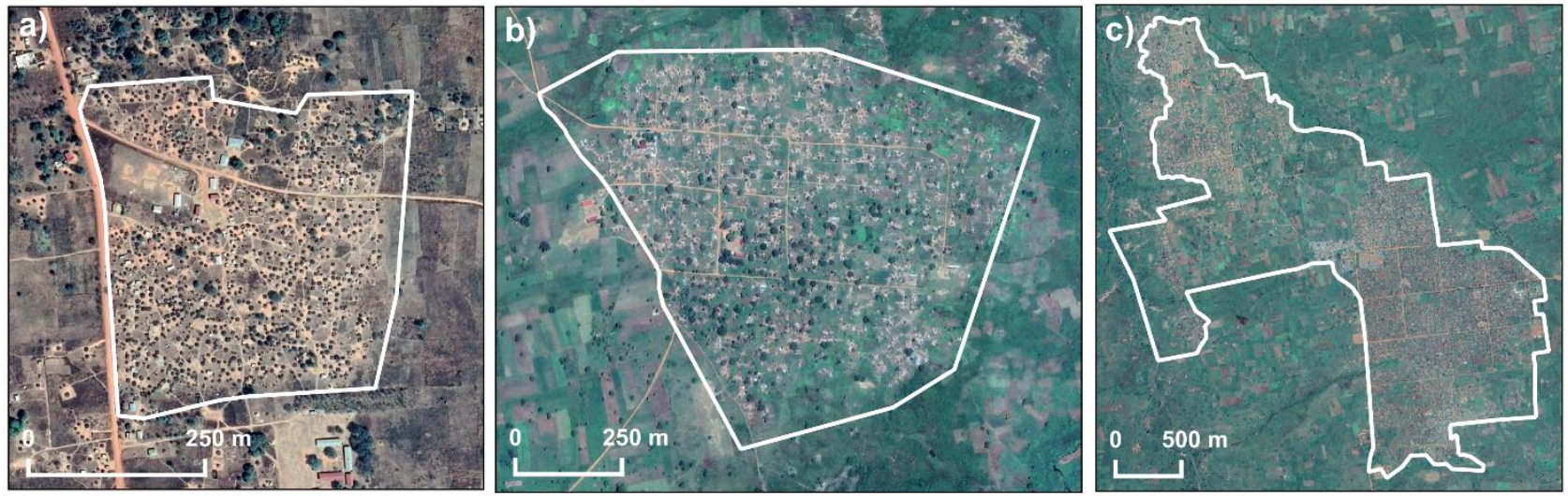

Figure 3. Refugee settlement boundaries established by UNHCR (white outline) at a) Mireyi, b) Boroli I, and c) Ayilo I with background Google Maps-hosted satellite image base map.

\subsection{Human Settlement Datasets}

We examined four satellite-derived broad-scale human settlement products at the 30 study refugee settlements. The Global Human Settlement Layer with Sentinel-2 (GHSBUILT-S2; [2]) offers 10 meter resolution global-scale coverage of probabilistic settlement presence based on a convolutional neural net $(\mathrm{CNN})$ classification of Sentinel-2 Level 1C imagery from January 2017 through December 2018. GHS-BUILT-S2 was publicly released in November 2020. We initially examined settlement detection using $>1 \%$ and $>50 \%$ probability thresholds but adopted recommendations from [2] to use a $20 \%$ probability threshold for settlement detection in rural, low-density settlement regions. GHS-BUILTS2 has a nominal accuracy of $85 \%$ when using a detection probability threshold of greater than $20 \%$ in Africa, but there is no explicit mention of detection accuracy for refugee settlements. GHS-BUILT-S2 is available at https://ghsl.jrc.ec.europa.eu/ghs_bu_s2_2018.php.

The World Settlement Footprint (WSF; [3]) is a 10 meter resolution global-scale binary human settlement dataset based on multi-temporal Sentinel-1 Synthetic Aperture Radar (SAR, $10 \mathrm{~m}$ ) and Landsat $8(30 \mathrm{~m}$ ) imagery from 2014-2015 classified using a Support Vector Machine (SVM). WSF offers global-scale coverage with a nominal settlement detection accuracy of $86 \%$, and was publicly released in July 2020. WSF producers note that smaller structures made with building materials commonly found in refugee settlements (e.g., mud bricks and straw) were not consistently detected with WSF, but there is no quantitative assessment available to support this observation. WSF is available at https://figshare.com/articles/dataset/World_Settlement_Footprint_WSF_2015/10048412.

The High Resolution Settlement Layer (HRSL; [4]) is a 30 meter resolution population and settlement dataset with coverage across 140 countries and was released in December 2017. HRSL's binary settlement data are based on a CNN classification of buildings using $50 \mathrm{~cm}$ resolution Maxar imagery from 2011-2015. HRSL has an average precision and recall of $95 \%$ and $91 \%$, respectively, and $99 \%$ and $93 \%$ for Uganda, respectively. There is no mention of refugee settlements being considered in the development of the settlement detection approach or accuracy assessment. HRSL data are available at https://www.ciesin.columbia.edu/data/hrsl/.

The Geo-Referenced Infrastructure and Demographic Data for Development (GRID3; [5]) offers wall-to-wall coverage for 51 countries in sub-Saharan Africa and was made publicly available in April 2020. GRID3 is a vector (i.e., polygon) product based on Ecopia building footprints derived from $50 \mathrm{~cm}$ resolution Maxar imagery. Approximately $77 \%$ of imagery input to GRID3 for Uganda were acquired between 2016-2020 with 23\% from 2015 or earlier. Settlement extents are created by processing building footprint centroids to a 3 arc-second raster grid of building densities. Based on the underlying building density, polygons are classified as Built-Up Area (BUA; high density), Small Settlement Area (SSA; moderate density), or hamlet (low density). To capture any indication of settlement presence within GRID3, we merged all three settlement classes and refer to this combined 
coverage as GRID3 henceforth. As with other products, there is no mention of refugee settlements being considered in GRID3's development or validation but refugee settlements and other settlements with temporary structures are recognized as being difficult to detect. GRID3 data for Uganda are available at https://academiccommons.columbia.edu/doi/10.7916/d8-s1yg-pc20.

In addition to the four products above, we conducted preliminary analyses of the Landsat-based Global Human Settlement Layer (GHS-BUILT; https://ghsl.jrc.ec.europa.eu/ghs_bu2019.php), Global Urban Footprint (GUF; [57]), and the Global Artificial Impervious Area (GAIA; [58]). Since these products had zero or negligible coverage within study refugee settlements, we removed them from further analysis.

\subsection{Refugee Settlement Building Footprint Data}

Two different kinds of building footprint data were used for assessing the areal coverage and detection accuracy of the four settlement products. The open-source OpenStreetMap (OSM) building footprint dataset for Uganda includes 304,482 individual building footprints, covers a total area of $7.26 \mathrm{~km}^{2}$ across the 30 study settlements, and was created between 2017 and 2020 according to footprint timestamp data. There is no explicit accuracy assessment for OSM footprint data but their accuracy, completeness, and geo-precision are recognized to depend on settlement morphology, building density, and rooftop architecture [59]. The OSM footprint dataset is available at https://data.humdata.org/dataset/hotosm_uga_buildings.

We also used building footprints created through the Microsoft (MS) AI for Humanitarian Action program in partnership with the Humanitarian OpenStreetMap Team. This MS dataset spans Uganda and Tanzania and was generated using a deep neural net model trained with 1.2 million labeled buildings and Maxar very high resolution satellite imagery [60]. The MS dataset includes 58,544 individual building footprints that span a total area of $2.16 \mathrm{~km}^{2}$ across 27 study settlements; only Ayilo II, Boroli II, and Pagirinya lack MS footprint data. The reported precision and recall for the MS footprint dataset are $95 \%$ and $62 \%$, respectively, but is variable especially between urban and rural settings [61]. The MS building footprint dataset is available at https://github.com/microsoft/UgandaTanzania-Building-Footprints.

A fused building footprint product was created by merging the complementary OSM and MS building footprint datasets (Fig. 4). The OSM-MS fused dataset includes 317,416 individual building footprints across $8.47 \mathrm{~km}^{2}$ over all 30 refugee settlements; only 0.94 $\mathrm{km}^{2}$ was recorded in both OSM and HOT footprint datasets. OSM-MS building footprints have a median area of $0.60 \mathrm{~km}^{2}$ (mean: 2.05; min: 0.04; max: 14.93; std: 3.41), and there are a median 589 OSM-MS building footprints per $\mathrm{km}^{2}$ within a refugee settlement's UNHCR boundary (mean: 860, min: 68, max: 4213, std: 926). Even with the fused OSM-MS building footprint product, there are notable omission errors (e.g., Fig. $4 \mathrm{~b}-\mathrm{d}$ ), which we discuss below.

To support a pixel-wise validation of each settlement product, we prepared a 10 meter resolution raster georeferenced to the WSF product. We rasterized the fused OSM-MS building footprints to a binary settlement/non-settlement raster. In an effort to increase the likelihood of agreement with human settlement products, we considered any pixel intersecting an OSM-MS building footprint as a settlement pixel; any pixel lacking an OSM-MS building footprint was considered a non-settlement pixel. Rasterized building footprint coverage spans 0.04 to $14.93 \mathrm{~km}^{2}$ across the 30 study settlements (Table 1), and all mentions below of the OSM-MS building footprint dataset refer to the 10 meter resolution raster product rather than the input polygons. 

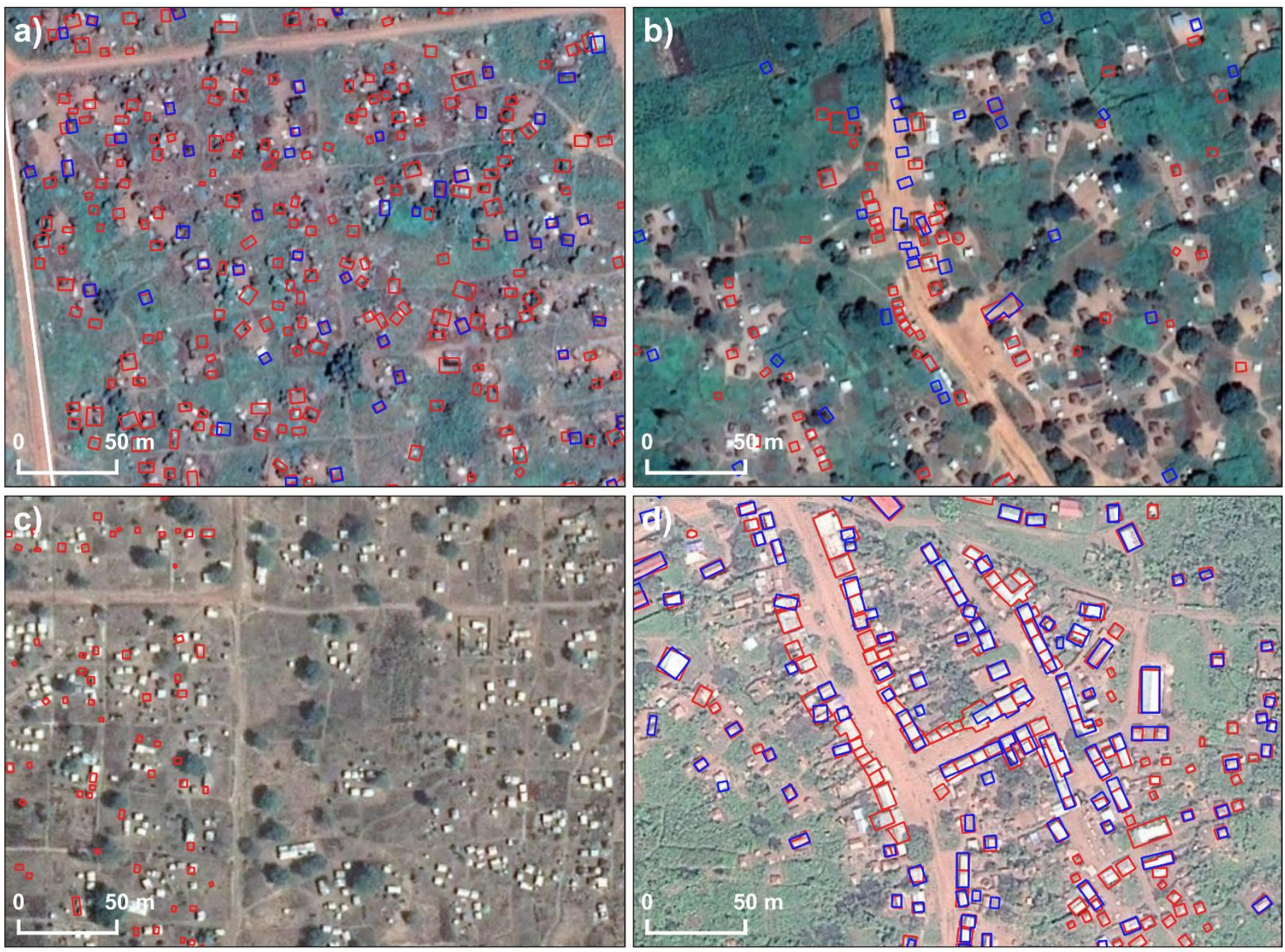

Figure 4. Example coverage of OSM (red polygons) and Microsoft (blue polygons) building footprints in the fused OSMMS building footprint dataset with Google Maps-hosted satellite image base map at a) Ayilo I, b) Imvepi, c) Palorinya, and d) Kyangwali refugee settlements.

\section{Methods}

This study has three objectives (Fig. 5): to assess the areal coverage of broad-scale human settlement products across 30 refugee settlements in Uganda, validate settlement product detection accuracy using OSM-MS building footprint data, and measure agreement in refugee settlement detection across the settlement products. To support intercomparison between settlement products and building footprint OSM-MS data, HRSL and GHS-BUILT-S2 were resampled and georeferenced to the 10 meter resolution WSF product, and GRID3 vector data were similarly rasterized at 10 meter resolution and georeferenced to WSF. Since WSF and HRSL were predominantly based on imagery from before 2016 -- and therefore are less likely to detect refugee settlements established in 2016 or later -- and GRID3 and GHS-BUILT-S2 predominantly used imagery acquired in 2016 or later, we report areal coverage, validation, and agreement results for pre-2016 refugee settlements (i.e., settlements established before 2016) separately from post-2016 refugee settlements (i.e., settlements established in 2016 or later). 


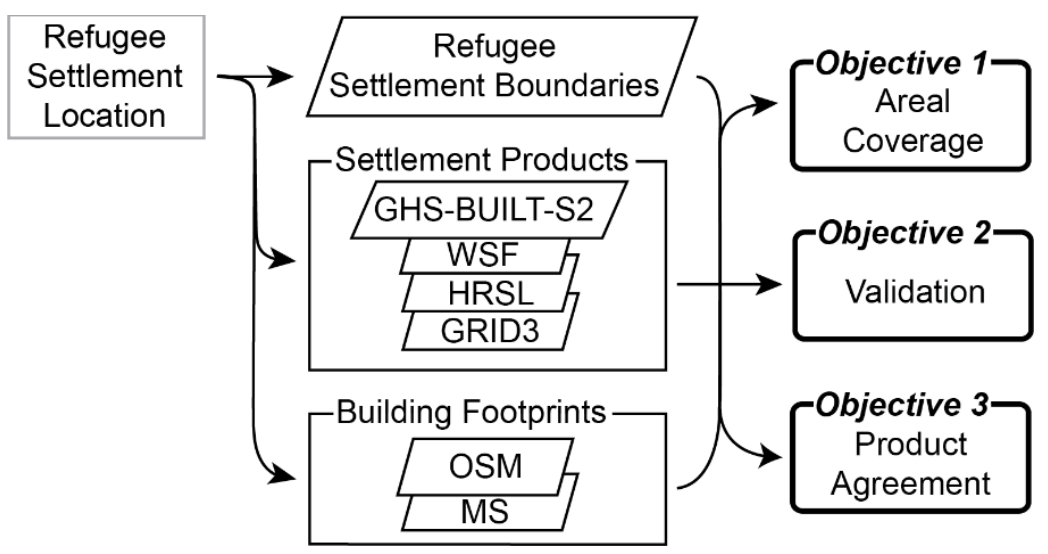

Figure 5. Methodological flowchart. GHS-BUILT-S2: Global Human Settlement Layer with Sentinel 2. WSF: World Settlement Footprint. HRSL: High Resolution Settlement Layer. GRID3: GeoReferenced Infrastructure and Demographic Data for Development. OSM: OpenStreetMap. MS: Microsoft.

\subsection{Objective 1: Measure areal coverage of settlement products at refugee settlements}

To measure potential under- or over-representation of refugee settlement area, we measured the areal coverage of each human settlement product at study refugee settlements at two scales. First, we measured the ratio of settlement product area to the UNHCR refugee settlement boundary area, which, as described above, may include large swaths of unpopulated land as well as non-refugee population settlements. Second, we compared human settlement product area to the total area of OSM-MS building footprints within each settlement's UNHCR boundary. Since settlement establishment partially informs whether a settlement can be detected by a given product, we considered pre- and post2016 settlements separately.

\subsection{Objective 2: Validate settlement product detection of refugee settlements}

We measured the detection accuracy of each human settlement product at refugee settlements by comparison with the 10 meter resolution OSM-Microsoft building footprint data. We measured the total area of "hit" (true positive, TP), "false alarm" (false positive, FP), "miss" (false negative, FN), and "none" (true negative, TN) pixels for each product's coverage within each settlement's UNHCR boundary (Table 2). With these values in hand, we calculated commonly used validation metrics to assess classification performance: Probability of Detection (POD, also known as Recall), Critical Success Index (CSI; [62]), F1-Score (F1), and False Alarm Rate (FAR, also known as the False Positive Ratio) (Table 3). POD indicates the proportion of building footprint area represented in a settlement's product coverage. CSI accounts for potential over- and under-detection of building footprint area by the settlement products. F1 provides additional sensitivity to detection of sparse features. Lastly, FAR indicates over-detection of building footprint area. All metrics range from $0-1$.

Table 2. Confusion matrix comparing settlement/non-settlement values as represented in human settlement products and the OSM-MS building footprint dataset. TP: True Positive. FP: False Positive. FN: False Negative. TN: True Negative.

\begin{tabular}{|c|c|c|c|}
\hline & & \multicolumn{2}{|c|}{ OSM-MS Building Footprints (Reference) } \\
\hline & & Settlement & Non-Settlement \\
\hline \multirow{2}{*}{$\begin{array}{c}\text { Human Settlement } \\
\text { Product }\end{array}$} & Settlement & Hit (TP) & False Alarm (FP) \\
\cline { 2 - 4 } & Non-Settlement & Miss (FN) & None (TN) \\
\hline
\end{tabular}

Table 3. Table of validation metrics and equations. 


\begin{tabular}{|c|c|}
\hline Probability of Detection (POD) & $\frac{\text { Hit }}{\text { Hit }+ \text { Miss }}$ \\
\hline Critical Success Index (CSI) & $\frac{\text { Hit }}{\text { Hit }+ \text { Miss }+ \text { False Alarm }}$ \\
\hline F1-Score (F1) & $\frac{2 * \text { Hit }}{2 * \text { Hit }+ \text { Miss }+ \text { False Alarm }}$ \\
\hline False Alarm Rate (FAR) & $\frac{\text { False Alarm }}{\text { False Alarm }+ \text { Hit }}$ \\
\hline
\end{tabular}

\subsection{Objective 3: Assess agreement between settlement products}

We next examined the agreement between GHS-BUILT S2, WSF, HRSL, and GRID3 in their detection of pre- and post-2016 refugee settlements. We made a multi-product agreement raster at 10 meter spatial resolution that represents the number of products with coverage per pixel within each settlement boundary. We measured the area detected by a single human settlement product (i.e., unique detection without agreement from another human settlement product) as well as the area detected by two, three, or four products (i.e., common detection by all human settlement products) within boundaries and over OSM-MS building footprints. We also measured the respective contributions of each human settlement product to each level of agreement (e.g., 1-4) to identify product-level differences in unique or multi-product agreements. To gauge how accuracy of detection changes with increased agreement, we measured the validation metrics from Objective 2 for the multi-product agreement raster relative to the OSM-MS building footprint dataset. Since the values in the multi-product agreement raster are mutually exclusive over space, we could not independently assess each value's detection accuracy fairly without being penalized for the footprints accurately detected by other values in the multi-product agreement raster. So, we measured validation metrics cumulatively by incorporating single (unique) coverage in the validation of two-product agreement area; incorporating one, two, and three-product coverage in the validation of the three-product agreement area, etc.

\section{Results}

\subsection{Objective 1: Measure areal coverage of settlement products at refugee settlements}

We found large differences in coverage between the four human settlement products within the UNHCR refugee settlement boundaries (Fig. 6). GHS-BUILT-S2, HRSL, and GRID3 have coverage across all 30 settlements but WSF didn't offer a single pixel at eight refugee settlements that were established at various dates spanning 1992 through 2016. GRID3 offers more than five-fold the coverage of other products within UNHCR settlement boundaries, and detected a median 65\% (min: $9 \%$; max: 100\%; std dev: $26 \%$ ) of the settlement boundary area for pre-2016 settlements and a median $28 \%$ (min: $11 \%$; max: $72 \%$; std dev: $18 \%$ ) of the boundary area for post-2016 settlements. HRSL has the second largest median coverage with $13 \%$ (min: $1 \%$; max: $49 \%$; std dev: $13 \%$ ) of pre-2016 settlements and $1 \%$ (min: $0 \%$; max: $26 \%$; std dev: $8 \%$ ) of post-2016 settlements. The median coverages of GHS-BUILT-S2 and WSF don't exceed $2 \%$ for pre- or post-2016 settlements, and the maximum areas covered by GHS-BUILT-S2 and WSF across all settlements are only $12 \%$ (i.e., Boroli I, established 2014) and 25\% (i.e., Olua II, established 2012), respectively. Note that the HRSL and WSF coverage of post-2016 settlements despite not using post-2016 source imagery results from detection of non-refugee populations within the settlement boundary prior to refugee arrival. 


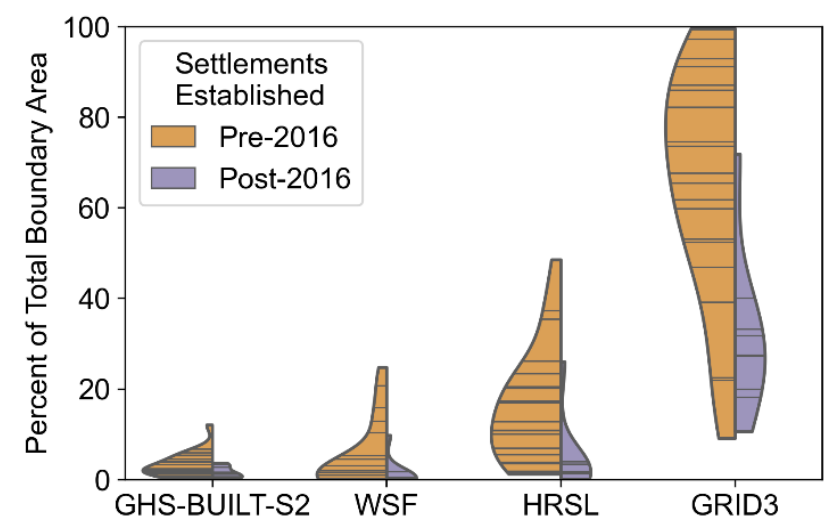

Figure 6. Violin plots of settlement product coverage as a percentage of the refugee settlement boundary area. Pre-2016 settlements were established before 2016 while post-2016 settlements were established in 2016 or later.

We next measured human settlement product coverage compared to OSM-MS building footprint coverage within each settlement's boundary. We found that GHS-BUILT-S2 and WSF underestimate the OSM-MS building footprint area by a median $0.30 \mathrm{~km}^{2}(\mathrm{~min}$ : $0.53 \mathrm{~km}^{2}$ overestimate; max: $11.80 \mathrm{~km}^{2}$; std dev: $2.50 \mathrm{~km}^{2}$ ) and $0.60 \mathrm{~km}^{2}$ (min: $0.61 \mathrm{~km}^{2}$ overestimate; max: $10.86 \mathrm{~km}^{2}$; std dev: $2.49 \mathrm{~km}^{2}$ ), respectively (Fig. 7). HRSL offers a closer approximation of building footprint area with a slight median underestimation of 0.04 $\mathrm{km}^{2}$ (min: $0.68 \mathrm{~km}^{2}$; max: $4.01 \mathrm{~km}^{2}$; std dev: $1.21 \mathrm{~km}^{2}$ ) while GRID3 grossly overestimates the OSM-MS footprint area by a median $1.69 \mathrm{~km}^{2}$ (min: $129.09 \mathrm{~km}^{2}$; max: $0.07 \mathrm{~km}^{2}$; std dev: $32.95 \mathrm{~km}^{2}$ ). Thus, while GRID3 may cover more of the area within a settlement boundary, this coverage is an over-estimation of building footprint area, and HRSL, instead, offers the best agreement to building footprint coverage. As above, pre-2016 settlements saw markedly better agreement than post-2016 settlements across all products, and HRSL had the most similar coverage for pre- and post-2016 building footprints. 

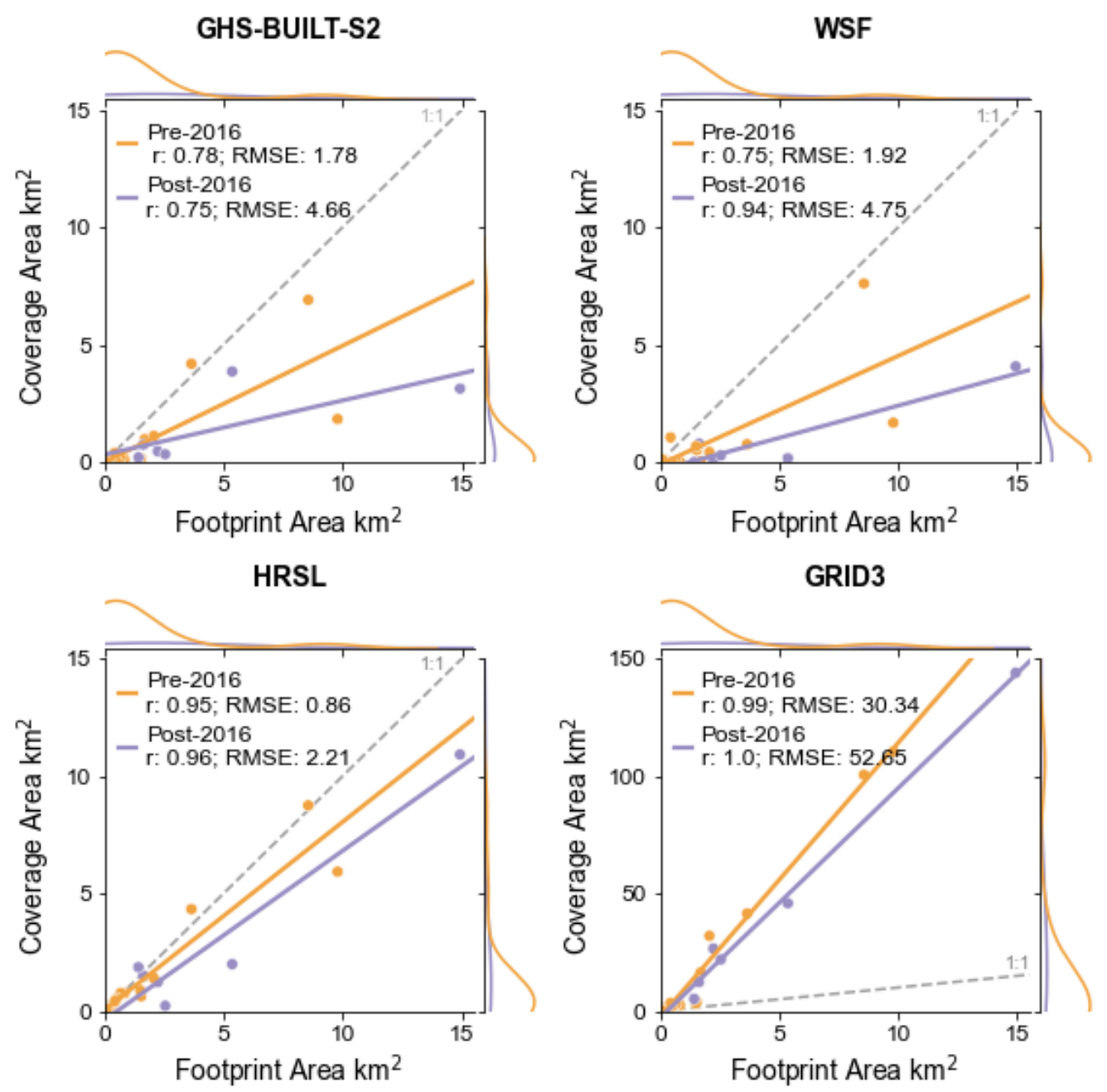

Figure 7. Scatterplots of human settlement product coverage compared to OSM-MS building footprint coverage for 30 study settlements. Orange and purple dots and lines of best fit represent pre2016 and post-2016 settlements, respectively. Gray dashed line indicates a 1:1 agreement.

\subsection{Objective 2: Validate settlement product detection of refugee settlements}

In our validation using the OSM-MS building footprint dataset, we found that the four settlement products -- GHS-BUILT-S2, HRSL, WSF, and GRID3 -- do not accurately detect refugee settlements. For pre-2016 settlements, the settlement products offer a median Probability of Detection (POD) of 0.26, Critical Success Index (CSI) of 0.13, F1-Score (F1) of 0.26, and False Alarm Rate (FAR) of 0.59. Settlement products fare worse for post2016 settlements, with a median POD of 0.17 , CSI of 0.09, F1 of 0.16, and FAR of 0.73. Of individual products (Fig. 8), GRID3 has the overall highest detection accuracy of pre-2016 refugee settlements with a median POD of 0.97 , CSI of 0.21 , and an F1of 0.38 but suffers from the highest median FAR of 0.75. HRSL has the second highest detection rate across all metrics and is only marginally below GRID3 for all metrics other than POD. GHSBUILT-S2 and WSF tend to have the lowest detection rates at less than 0.10 for all metrics other than F1. Detection rates are expected to be higher for pre-2016 settlements given their establishment prior to source image acquisition, yet even pre-2016 detection rates are far below each settlement product's nominal detection accuracy, which range from 85$99 \%$. These results point to a consistent under-detection of settlement as depicted in the OSM-MS building footprints dataset, an over-detection of settlement area that is not represented in the footprints dataset, with highly variable accuracies settlement to settlement (See Figure A1). 

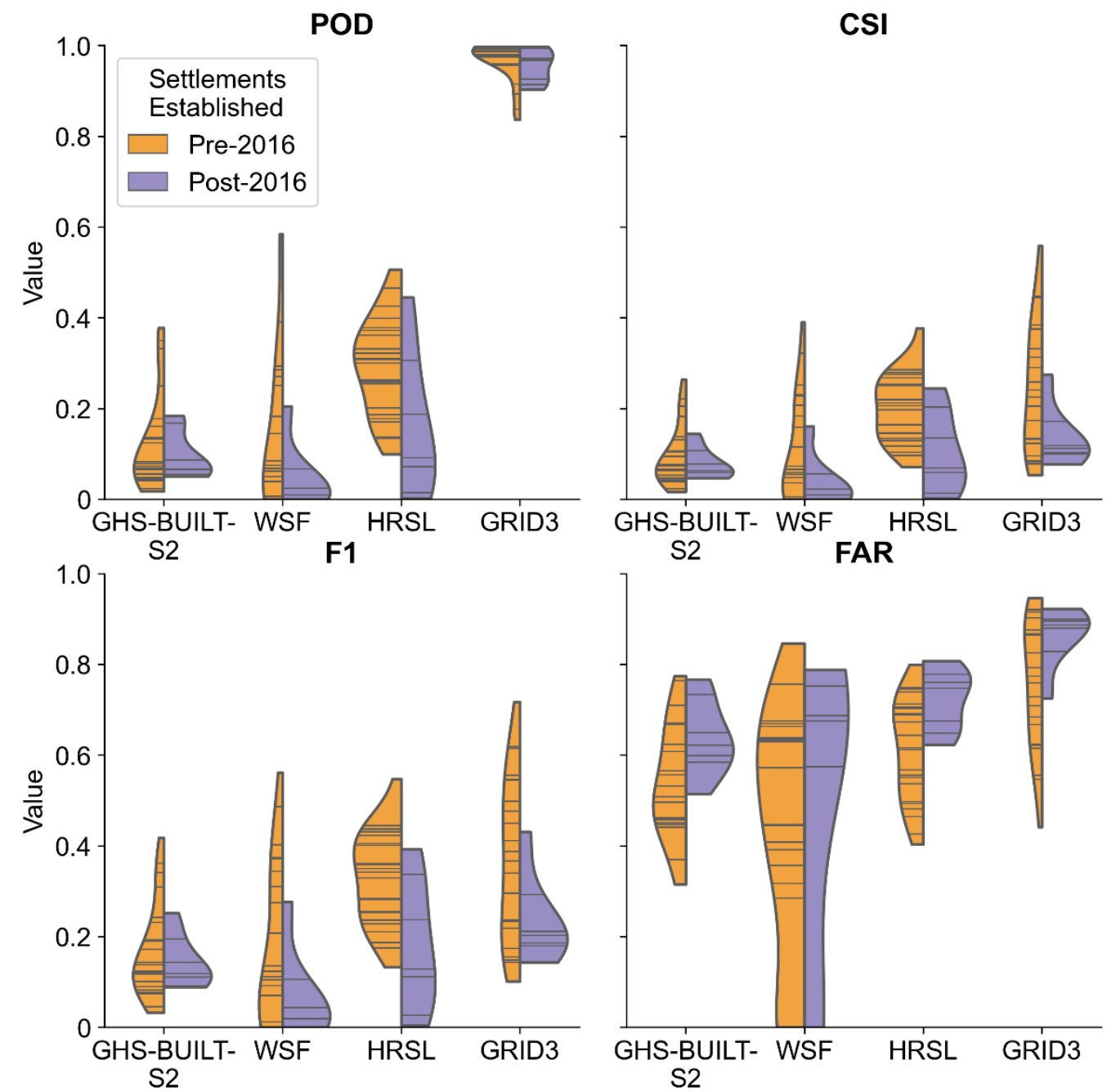

Figure 8. Violin plots of Hit Rate (HR), Probability of Detection (POD), Critical Success Index (CSI), F1-Score (F1), and False Alarm Rate (FAR) validation metrics for individual settlement products compared to the OSM-MS building footprint dataset for pre- and post-2016 settlements.

There was wide variation in detection with GRID3 most often offering superior accuracy despite its high FAR. Mireyi, for example, is a small refugee settlement demarcated by a boundary $0.20 \mathrm{~km}^{2}$ in size with $0.11 \mathrm{~km}^{2}$ of building footprint coverage. Mireyi was established in 1994 meaning that all four products are based on source imagery acquired decades after the earliest refugee arrivals yet these products offer disparate views of the settlement (Fig. 9). GRID3 has complete coverage of all OSM-MS building footprints $(\mathrm{POD}=0.10)$ but yields extensive false alarms elsewhere within the settlement $(\mathrm{FAR}=0.44)$. By contrast, HRSL tends to only capture the central region of the settlement $(\mathrm{POD}=0.51)$ and overlooks settled regions near the boundary (FAR=0.40). WSF and GHS-BUILT-S2 offer progressively less coverage but manage to capture some settled areas overlooked by HRSL. Considering the oldest settlements of Kyangwali (1960) and Oruchinga (1961) (see Fig. A2), we find that, in contrast to overall pre-2016 settlement detection trends (Fig. 8), GHS-BUILT-S2 had the highest detection rates in terms of CSI and F1. Moving several decades later to the next established settlements of Rhino Camp and Elema, established in 1980 and 1992, respectively, HRSL excelled in all detection metrics other than POD, which GRID3 once again led. These are exceptions, however, since settlements established in the mid-1990s through the most recently established settlements (such as Boroli I and Ayilo I, below) were best detected by GRID3 across detection metrics. 
S2 True Color

Mireyi - 1994

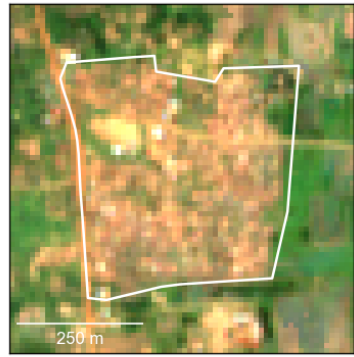

Boroli I - 2014
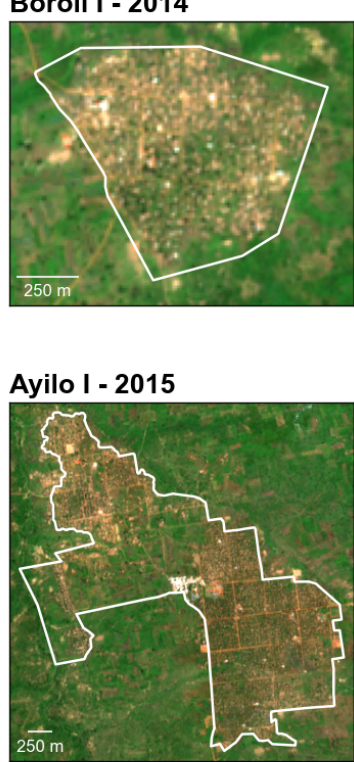

GHS - BUILT - S2

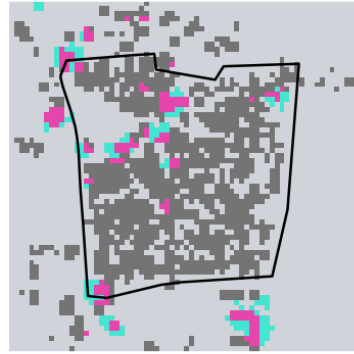

POD: 0.07: CSI: 0.06

F1: 0.12; FAR: 0.44

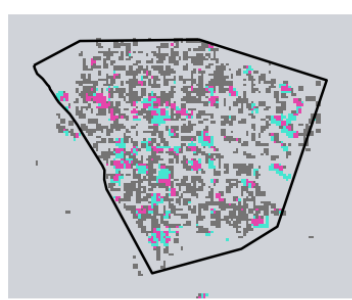

POD: 0.16; CSI: 0.14 F1: 0.24; FAR: 0.51

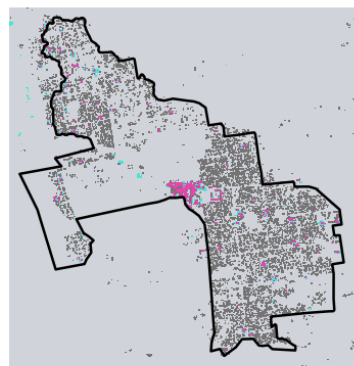

POD: 0.07 ; CSI: 0.06 F1: 0.12; FAR: 0.37

- Hit Miss
HRSL

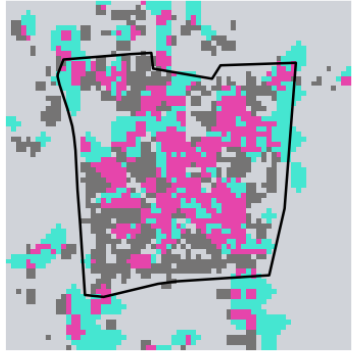

POD: 0.51 ; CSI: 0.38 F1: 0.55; FAR: 0.4

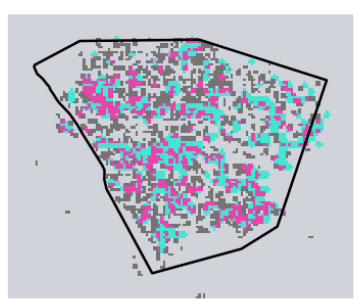

POD: 0.43 ; CSI: 0.29 F1: 0.45 ; FAR: 0.54

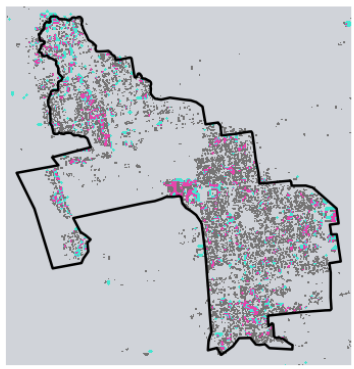

POD: 0.17 ; CSI: 0.15

F1: 0.26 ; FAR: 0.49

False None
WSF

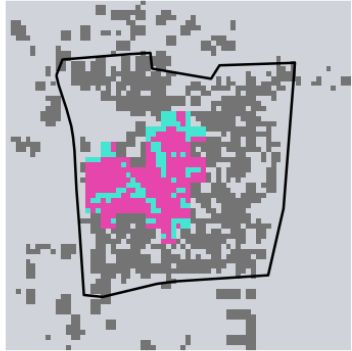

POD: 0.25 ; CSI: 0.23

F1: 0.37 ; FAR: 0.29

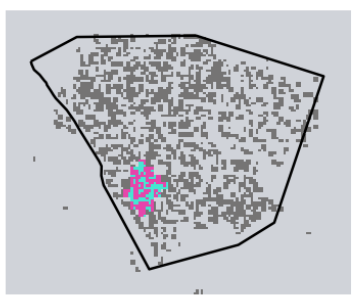

POD: 0.05; CSI: 0.05 F1: 0.09; FAR: 0.41

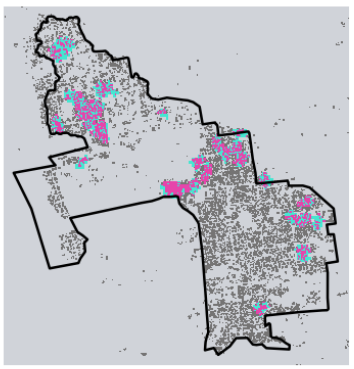

POD: 0.18; CSI: 0.16

F1: 0.27; FAR: 0.45
GRID3

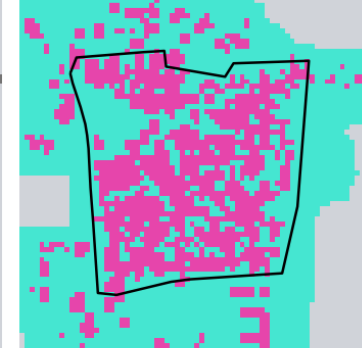

POD: 1.0; CSI: 0.56 F1: 0.72; FAR: 0.44
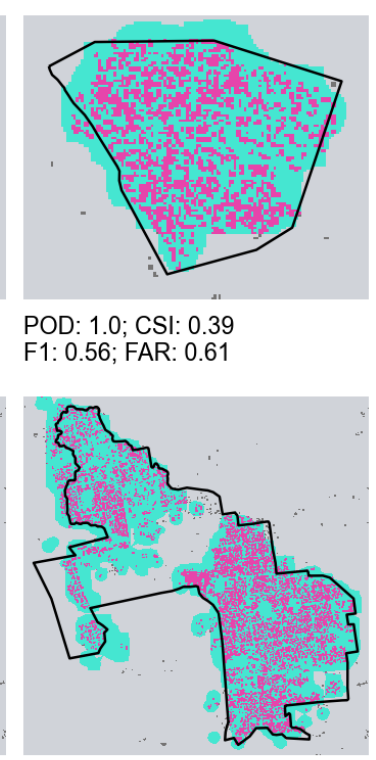

POD: 0.99; CSI: 0.38 F1: 0.55 ; FAR: 0.62

Figure 9. Settlement-level validation maps and validation metrics for all four settlement products at Mireyi, Boroli I and Ayilo I. Validation metrics are evaluated relative to OSM-MS building footprint coverage within settlement boundaries.

\subsection{Objective 3: Assess agreement between settlement products}

Given the at times overlapping coverage between the four human settlement products, we next examined the amount and accuracy of multi-product agreement. For pre2016 settlements, we found that nearly half $(45 \%)$ of the median coverage within a settlement boundary was unique to a single settlement product. This prevalence of unique detection and the rapidly decreasing coverage of two- $(17 \%)$, three- $(3 \%)$, and four- $(<1 \%)$ product agreement (Fig. 10) suggest high disagreement between the four settlement products. A similar trend in declining coverage with greater levels of agreement was measured in post-2016 settlements and points to an overall low agreement between products in their detection of refugee settlements. GRID3 is almost entirely responsible for unique detection within refugee settlements by providing $99 \%$ of single product coverage (Table 4). GRID3 is also present at all locations of detection by other products; in effect, there is not a single pixel detected by GHSL-BUILT-S2, HRSL, or WSF that is not also detected by GRID3. After GRID3, HRSL contributes zero unique detection but offers the second most coverage for sites detected by two or three products, while GHSL-BUILT-S2 and WSF offer zero unique detection and contribute the least to two- or three-product agreement coverage. 


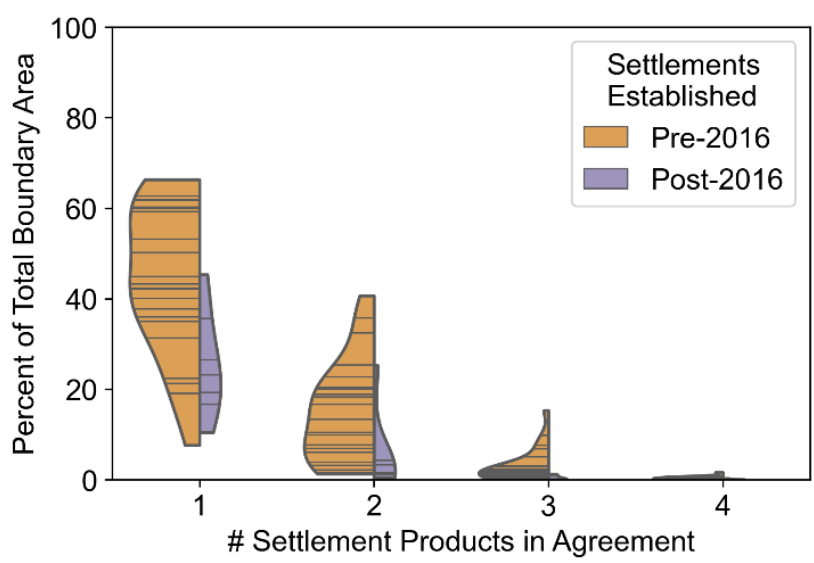

Figure 10. Violin plots of the area of settlement product agreement reported as a percentage of the UNHCR settlement boundary area for settlements established pre- and post-2016.

Table 4. Portion of each settlement product's contribution to areas with single or multi-product agreement for settlements established pre- or post-2016. All four products have $100 \%$ contribution to locations where four products are in agreement; not shown in table.

\begin{tabular}{|c|c|c|c|c|}
\hline & & \multicolumn{2}{|c|}{ \# Settlement Products in Agreement } \\
\hline \multirow{2}{*}{ GHS-BUILT-S2 } & $\begin{array}{c}\text { Settlement Es- } \\
\text { tablishment }\end{array}$ & $\mathbf{1}$ & $\mathbf{2}$ & $\mathbf{3}$ \\
\cline { 2 - 5 } & Pre-2016 & 0.00 & 0.28 & 0.66 \\
\hline \multirow{2}{*}{ HRSL } & Post-2016 & 0.00 & 0.30 & 0.68 \\
\cline { 2 - 5 } & Post-2016 & 0.00 & 0.51 & 0.75 \\
\hline \multirow{2}{*}{ WSF } & Pre-2016 & 0.00 & 0.52 & 0.70 \\
\cline { 2 - 5 } & Post-2016 & 0.00 & 0.21 & 0.59 \\
\hline \multirow{2}{*}{ GRID3 } & Pre-2016 & 0.99 & 0.18 & 0.62 \\
\cline { 2 - 5 } & Post-2016 & 1.00 & 1.00 & 1.00 \\
\hline
\end{tabular}

Twenty-one of the 30 study settlements have some coverage by all four products, eight settlements have coverage by three settlement products, and a single settlement (Agojo) only has coverage by two products (Fig. A3). The majority of multi-product agreement occurs in built-up regions with densely arranged, large, and highly reflective structures (Fig. 11). The multi-product agreement is likely associated with refugee settlement administration or UNHCR coordination while individual, small-scale refugee dwellings broadly evade detection by products other than GRID3. The absence of agreement across much of the largest refugee settlements (e.g., Bidi Bidi, Imvepi, and Kiryandongo) reflects the openness and broad absence of structures. Multi-product agreement outside of settlement boundaries is not uncommon (e.g., Boroli II, Elema, Mungula I, etc.) and may be associated with dwelling spillover (e.g., Maaji I), market structure construction (e.g., Pagirinya), and, less commonly, nearby non-refugee settlements (e.g., Lobule). The prevalence of multi-product agreement outside the UNHCR settlement boundaries suggests that the space directly influenced by refugees and settlement-level land use is not always encapsulated by refugee settlement boundaries, a finding echoed in [46]. 

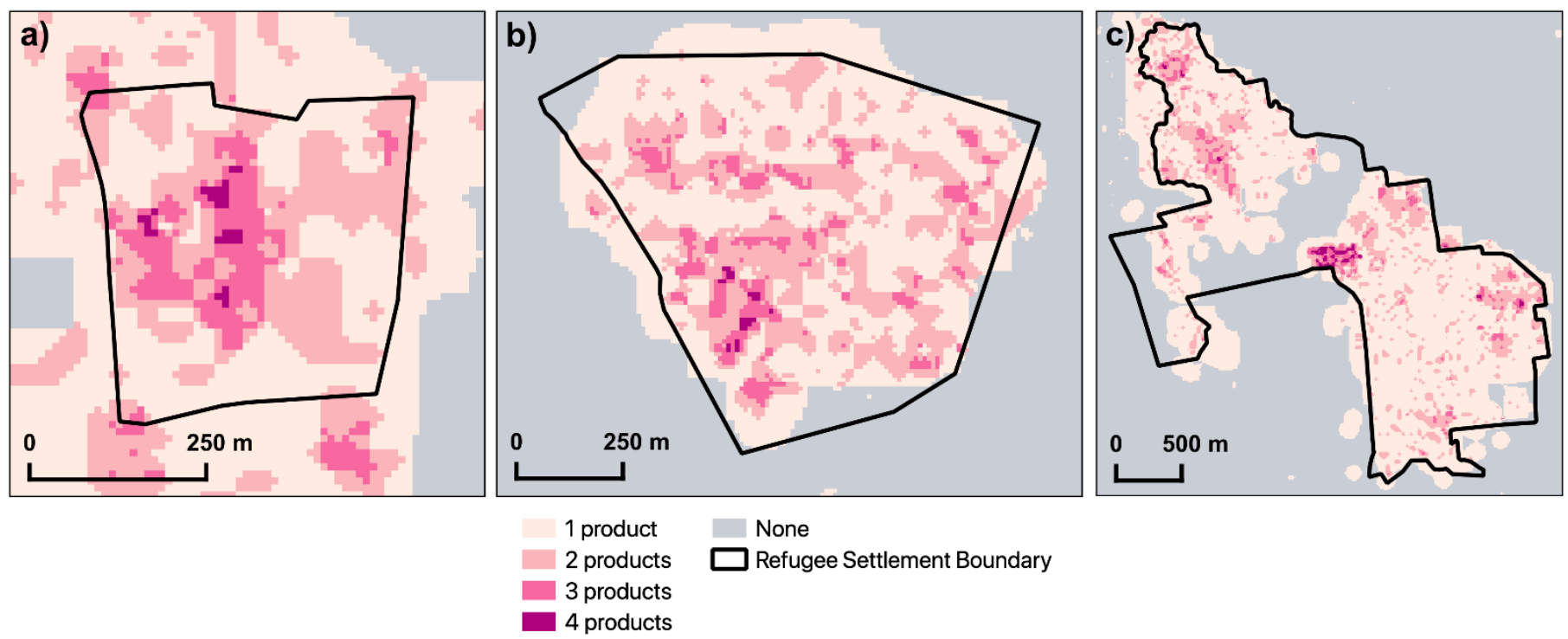

Figure 11. Maps of agreement between four settlement products at a) Mireyi, b) Boroli I, and c) Ayilo I. "1 product" indicates unique coverage by a single product. " 2 products", "3 products", and " 4 products" indicate the number of settlement products that share coverage. "None" indicates zero coverage. Note that the spatial scale of settlement maps varies.

We found that increasing agreement between settlement products also improved POD, CSI, and F1 and decreased FAR (Fig. 12; Fig. A4). The largest gain in accuracy occurred with the transition from unique detection by a single product (i.e., GRID3, as explained above) to agreement by two products (usually HRSL and GRID3) with little subsequent improvement in accuracy with the transition from two-product agreement to three- or four-product agreement. POD showed the greatest overall increase from unique detection by a single product to multi-product agreement -- likely because it overlooks false alarms -- while CSI, F1, and FAR were much more constrained in their incremental changes between agreement levels. Detection accuracy of pre-2016 settlements benefited more from increasing agreement compared to post-2016 settlements, which is expected given the overall higher accuracy of detection at pre-2016 settlements. 

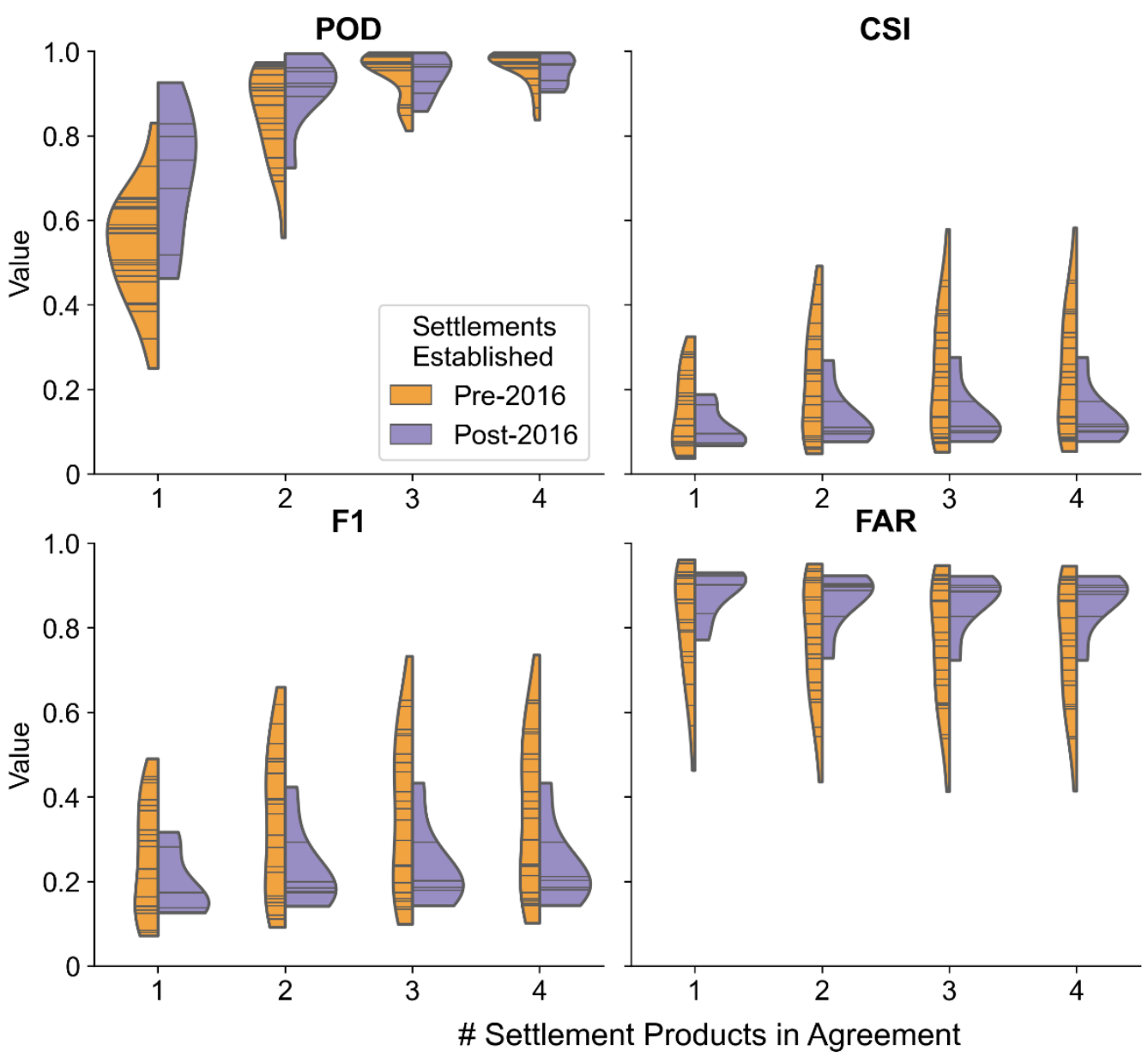

Figure 12. Violin plots of accuracy metrics, Probability of Detection (POD), Critical Success Index (CSI), F1-Score (F1), and False Alarm Rate (FAR) for multi-product agreement sites in comparison to OSM-MS building footprint coverage in settlements established before and in or after 2016. "1 product" indicates unique coverage by a single product. " 2 products", " 3 products", and " 4 products" indicate the number of settlement products that share coverage.

\section{Discussion}

This study is the first to systematically examine how well refugee settlements are captured by leading satellite data-based human settlement products, GHS-BUILT-S2, WSF, HRSL, and GRID3. Overall, we found generally low coverage within refugee settlements to begin with, which resulted in low detection accuracy, and consistently high FAR for products often in excess of 0.50 with GRID3 consistently reaching a FAR above 0.80 . GRID3 tends to provide the most coverage within a settlement's boundary but greatly over-represents the building footprint coverage within settlement boundaries, leading to high detection accuracies (POD, CSI, F1) but also high FAR. HRSL captured far less area than GRID3 but better approximates building footprint coverage within refugee settlement boundaries, and often has comparable CSI and F1 as GRID3 as well as a lower FAR. That HRSL does so well at estimating overall footprint area but has low detection accuracy suggests that HRSL provides an adequate allocation of settlement area but that its coverage is not correctly located within the settlement. GHS-BUILT-S2 and WSF tend to capture much less area within refugee settlement boundaries, underestimate building footprint coverage, and have the lowest detection accuracies albeit with the lowest FARs. Multiple products find common detection in regions with dense arrangements of buildings or with exceptionally large buildings, with similar results to [6,33], but there are few gains in detection accuracy when combining more than two different products.

What underlies the poor coverage and low detection of refugee settlements? While a building-level examination is beyond the scope of this study, the small size of buildings 
in study refugee settlements likely poses a central challenge to detection. This is suggested in the higher detection rates of GRID3 and HRSL, achieved with $50 \mathrm{~cm}$ resolution source imagery that is much more capable of resolving small buildings. Meanwhile, the $10 \mathrm{~m}$ resolution imagery used by GHS-BUILT-S2 and 10-30 m resolution imagery used by WSF increases the likelihood of capturing mixed pixels that may include buildings as well as surrounding vegetation, soil, and, less so, infrastructure. GHS-BUILT-S2 and WSF tend to overlook small buildings typical of family dwellings but do capture larger buildings, which tend to be administrative in function.

Settlement morphology can also affect detection rates as GHS-BUILT-S2 and WSF capture regions of densely clustered buildings that effectively offer a spatially contiguous settlement signal. For many settlements, WSF and GHS-BUILT-S2 exclusively detect structures in densely built-up regions. Such densely arranged buildings contribute to settlement detection accuracy and underlie the pattern of 3- and 4-product agreement (Fig. 11; Fig. A3). Morphology also influences FAR since false alarms most often occur in open, vegetated lands immediately adjacent to buildings rather than infrastructure. This is especially prominent with GRID3 data due to the processing step of buffering Ecopia building footprints that are at the core of GRID3 coverage. The resulting buffer around buildings that are isolated from others contributes to consistently higher FAR rates for GRID3, and is most pronounced for settlements that are diffusely settled (Fig. 9; Fig. A2).

The timing of settlement establishment can also contribute to divergent areal coverage and detection accuracy. We found that settlements established before 2016 were regularly better detected than settlements established in 2016 or later, which was mainly a consequence of the pre-2016 acquisition of satellite imagery used to generate the settlement products. However, this study showed that even the earliest and most populated refugee settlements of Kyangwali (1960), Oruchinga (1961), and Rhino Camp (1980) are poorly detected by all four settlement products despite these settlements being persistently inhabited for decades before satellite image acquisition. It is also possible that seasonal and phenological conditions at the time of image acquisition were not favorable for refugee settlement detection $[49,63]$; however, the specific dates of imagery used in generating the human settlement product coverage over Uganda here were not available to the study.

More difficult to consider is how the characteristics of buildings within refugee settlements compare to the buildings and settlements used to train and validate the settlement detection approaches of the four human settlement products considered here. Image classification approaches for remote sensing-derived global settlement products are commonly trained and evaluated on densely populated human settlements $[6,24,64]$. If a training dataset did not include refugee or other informal settlements that have construction materials and morphologies distinct from cities and towns that are typically used to train and validate a detection approach, it is likely that settlement detection approaches would have struggled to capture study refugee settlements. Indeed, as described above, there is no evidence that refugee or informal settlements were included in product training or validation. It is worth noting that Ugandan settlements are likely easier to detect than many other refugee settlements in Sub-Saharan Africa that have far lower building densities and lack durable roofing materials and impervious surfaces that would be easier to detect.

Low coverage and poor accuracy of refugee settlement detection is of concern for the producers of human settlement datasets who seek accurate detection of where humans live. Within a settlement, inconsistent and incomplete detection of settlements distorts our understanding of refugee land use. As described above, the UNHCR boundaries used in this study are established for settlement planning purposes before refugee arrival and usually do not represent the actual extent of refugee dwellings or land use. After refugee arrival, the collection of refugee dwellings and administrative buildings make up a functional settlement extent that reflects the actual distribution of the refugee population's footprint within the encompassing UNHCR boundary. Having an inaccurate representation of this functional settlement extent means that the spatial allocation and configuration 
of housing, infrastructure, and household agricultural plots are similarly distorted. While helpful for monitoring settlement land use dynamics, having functional settlement extents would also allow researchers to pivot from relying on the centroid of a refugee settlement as the principal geographic identifier.

There are also cascading consequences for modeled estimates of population driven by remote sensing-based human settlement data. Settlement data help refine the spatial allocation of administrative population data in unmapped or otherwise difficult to access regions and inform monitoring, planning, and assessments of development targeting, economic productivity, as well as humanitarian intervention [11,12,35,39]. We examined how well HRSL estimates the refugee population in each settlement by comparing HRSL-estimated populations to UNHCR-reported settlement populations (Table 1). We find that HRSL consistently underestimated settlement-level refugee populations across the 30 study settlements (Fig. 13). HRSL has a median underestimation of 6316 and 57,869 people for pre- and post-2016 settlements, respectively, and undercounts the total population across all 30 settlements by 837,751 people accounting for only $59 \%$ of the total refugee population in Uganda.

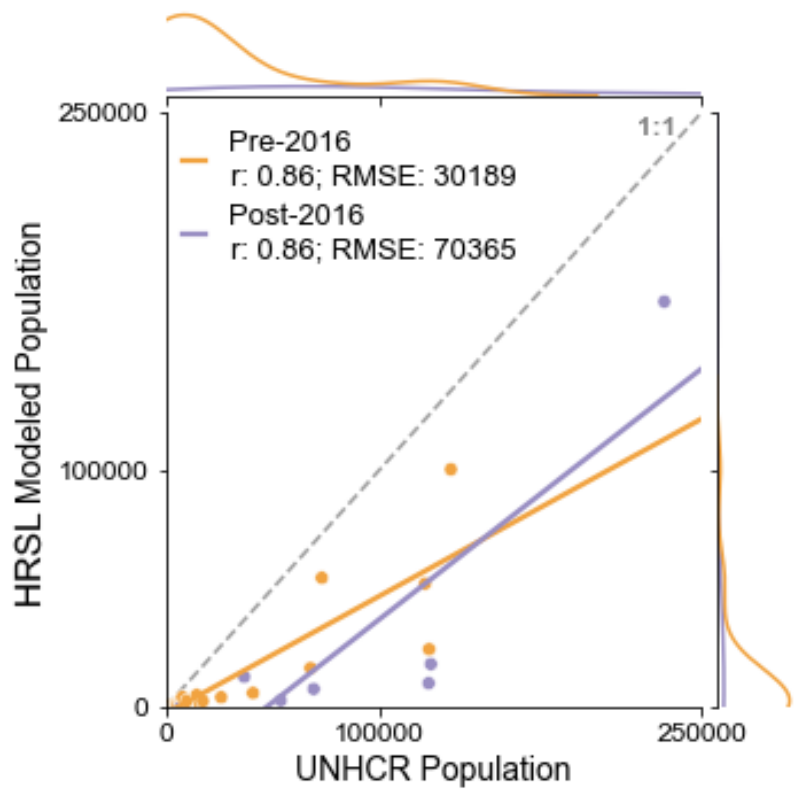

Figure 13. Scatterplot of refugee settlement-level UNHCR-reported populations compared to modeled population estimates from HRSL.

These settlement-level population estimates based on HRSL data are almost certainly an underestimation of refugee populations for three reasons. First, we showed that HRSL underestimates the settlement area at most refugee settlements. Second, the settlement area detected by HRSL that drives the population allocation may include non-refugee settlements located within UNHCR boundaries; this is the case at settlements such as Bidi Bidi, Kyangwali, Imvepi, and Rhino Camp. Since settlement area measurements may be inflated due to the presence of non-refugee settlements, the derived population estimates would be even less if only refugee settlements were being considered, which would result in an even larger underestimation. Third, since refugees are excluded from national census data, the administrative population being allocated to detected refugee settlement pixels is lower than the actual total population if refugees were included.

As is apparent, a more inclusive approach -- spatially, temporally, and thematically -- to broad-scale detection of refugee and other small-scale human settlements is needed. First and foremost, refugee settlement locations and areas should be included in the training and validation of remote sensing-based human settlement product generation and explicit accuracies should be reported; this will help clarify the relevance of broad-scale human settlement products for detection of refugee and other small-scale settlements. 
Second, the disparate detection accuracies between GHS-BUILT-S2 (10 $\mathrm{m}$ resolution source imagery) and WSF (10-30 m resolution source imagery) compared to GRID3 and HRSL (0.5 meter resolution source imagery) suggest that automated approaches using very high resolution imagery to detect buildings greatly improve small-scale refugee settlement detection accuracy [6]. While several localized studies have used moderate resolution satellite imagery (i.e., Landsat or Sentinel-2) to capture refugee settlements (e.g., $[41,46])$, such local successes have not yet translated to broad-scale automated detection of refugee settlements. Third, the establishment of new refugee settlements each year to support the growing global refugee population quickly makes human settlement datasets out-of-date, and is the principal reason for low detection accuracies for post-2016 settlements compared to pre-2016 settlements. In order to capture new refugee settlements, and not only document the growth of existing settlements, remote sensing-based human settlement datasets need timely updates at least every year and cannot linger as static, outdated snapshots of where people live, refugees or otherwise.

This study offered the first systematic analysis of refugee settlement presence within satellite-derived human settlement datasets but was limited in several ways. The diversity of image dates used to produce each of the four products made it uncertain whether a settlement had even been established when imagery was acquired for a given product. Examining coverage at settlements established before the earliest acquired imagery in 2011 helped address this uncertainty, but having a georeferenced metadata product labeling the specific image dates used in each product would have completely clarified the ambiguous product timing at settlements. Though the OSM-MS building footprint dataset was based on imagery collected over 2017-2020, it likely underrepresents the actual collection of buildings in some settlements, which would have contributed to greater FAR than was warranted. Furthermore, using building footprints for validation purposes introduces semantic dissimilarities between the cartographic representation of settlement in each of the products and the use of building footprints for independent validation.

There are ample opportunities for future work to build on the present study. While the study was set in Uganda to benefit from the wealth of ancillary data on refugee settlement boundaries and building footprints that are not systemically available in other refugee-hosting countries, future work would benefit from a broader sample of refugee or internally displaced persons (IDP) settlements in multiple countries that offer even more morphologic diversity. Including additional detail on the size, type, and construction material of structures being detected or excluded by settlement products would be helpful to target improvements in further human settlement products. Similarly, characterizing refugee settlement detection in terms of spectral or textural conditions or quantifying the influence of building size or building density on detection success would offer tailored suggestions for improved detection of small-scale settlements. A comparison between localized refugee settlement detection approaches using high resolution imagery (e.g., $[33,34,36])$ and GHS-BUILT-S2, WSF, HRSL, and GRID3 would also help demonstrate whether broad-scale products are fit for humanitarian purposes. A follow-on assessment of refugee settlement detection in next-generation human settlement products such as WSF-Evolution, the next iteration of GHS-BUILT, or products based on sub-annual or annual very high resolution imagery from Planet or Maxar would also be valuable. Finally, developing a comprehensive assessment of population estimations in refugee settlements informed by satellite-based human settlement products (e.g., [11,12]) would illuminate refugee, migration, and development policy implications of this study's findings.

\section{Conclusion}

This study presents the first systematic analysis of refugee settlement detection in satellite-based broad-scale human settlement products. Across 30 refugee settlements in Uganda, four human settlement products -- GHS-BUILT-S2, WSF, HRSL, and GRID3 -and 317,416 building footprints for independent validation, this study found that settlement products offered low to moderate detection accuracies, a high rate of false alarm, 
and tend to agree in detection within settlements only at the very largest or reflective buildings or in localized regions of high building density. GRID3 and HRSL, based on very high resolution satellite imagery, offered the greatest coverage and detection accuracy and contributed the most unique detections of building footprints within refugee settlements. While these results are explicitly associated with refugee settlements in Uganda, similarly low detection rates are likely present at other small-scale or informal settlements around the world. Such inadequate detection of refugee settlements raises concerns about the continental or global accuracy of human settlement products as well as the quality of follow-on geospatial products such as population maps based in part on remote sensing-based human settlement data.

Settlement products tout exceptional nominal accuracies above ninety percent for detecting human settlements, yet the poor detection of refugee settlements shows the need for a more inclusive human settlement detection approach. A more inclusive approach could involve formally incorporating refugee settlements in the training and testing of human settlement products, reporting of detection accuracy at refugee settlements, using very high resolution imagery to detect small-scale dwellings and other structures that often make up refugee settlements, and providing annual updates to human settlement datasets that keep pace with the establishment of new refugee settlements around the world. The accurate inclusion of refugee settlements in broad-scale human settlement products would appropriately recognize refugee settlements as being long-term residences for millions of people and improve the cartographic visibility of refugees and refugee settlements in data-driven development and climate hazard mitigation efforts.

Author Contributions: Conceptualization, J.V.D.H.; methodology, J.V.D.H. and H.K.F.; software, H.K.F.; validation, J.V.D.H. and H.K.F.; formal analysis, J.V.D.H. and H.K.F.; writing - original draft preparation, J.V.D.H. and H.K.F.; writing - review and editing, J.V.D.H. and H.K.F.; visualization, J.V.D.H. and H.K.F.; funding acquisition, J.V.D.H. All authors have read and agreed to the published version of the manuscript.

Funding: This research was funded by the National Aeronautics and Space Administration (80NSSC18K0311).

Data Availability Statement: OSM (OpenStreetMap) refugee settlement boundary data for Uganda are available at https://data2.unhcr.org/en/documents/details/74116 (accessed on 1 December 2020). GHS-BUILT-S2 data are available at https://ghsl.jrc.ec.europa.eu/ghs_bu_s2_2018.php (accessed on 1 December 2020). WSF data are available at https://figshare.com/articles/dataset/World_Settlement_Footprint_WSF_2015/10048412 (accessed on 1 December 2020). HRSL data are available at https://www.ciesin.columbia.edu/data/hrsl/ (accessed on 1 December 2020). GRID3 data for Uganda are available at https://academiccommons.columbia.edu/doi/10.7916/d8-s1yg-pc20 (accessed on 1 December 2020). OSM footprint data for Uganda are available at https://data.humdata.org/dataset/hotosm_uga_buildings (accessed on 1 December 2020). MS building footprint data are available at https://github.com/microsoft/Uganda-Tanzania-Building-Footprints (accessed on 1 December 2020).

Acknowledgments: The authors thank Anna Ballasiotes for their contribution to a preliminary assessment of refugee settlement detection. We thank Bob Chen, Sergio Freire, Thomas Kemper, and Mattia Marconcini for productive discussions around human settlement mapping in and outside of refugee settings. We thank Nancy Searby and Betzy Hernandez and the broader Human Planet Group on Earth Observations community for their encouragement and support in undertaking this study. We acknowledge the Ampinefu ("Mary's River") band of the Kalapuya people who are the original inhabitants of the land now occupied by Oregon State University.

Conflicts of Interest: The authors declare no conflict of interest.

\section{Appendix A}




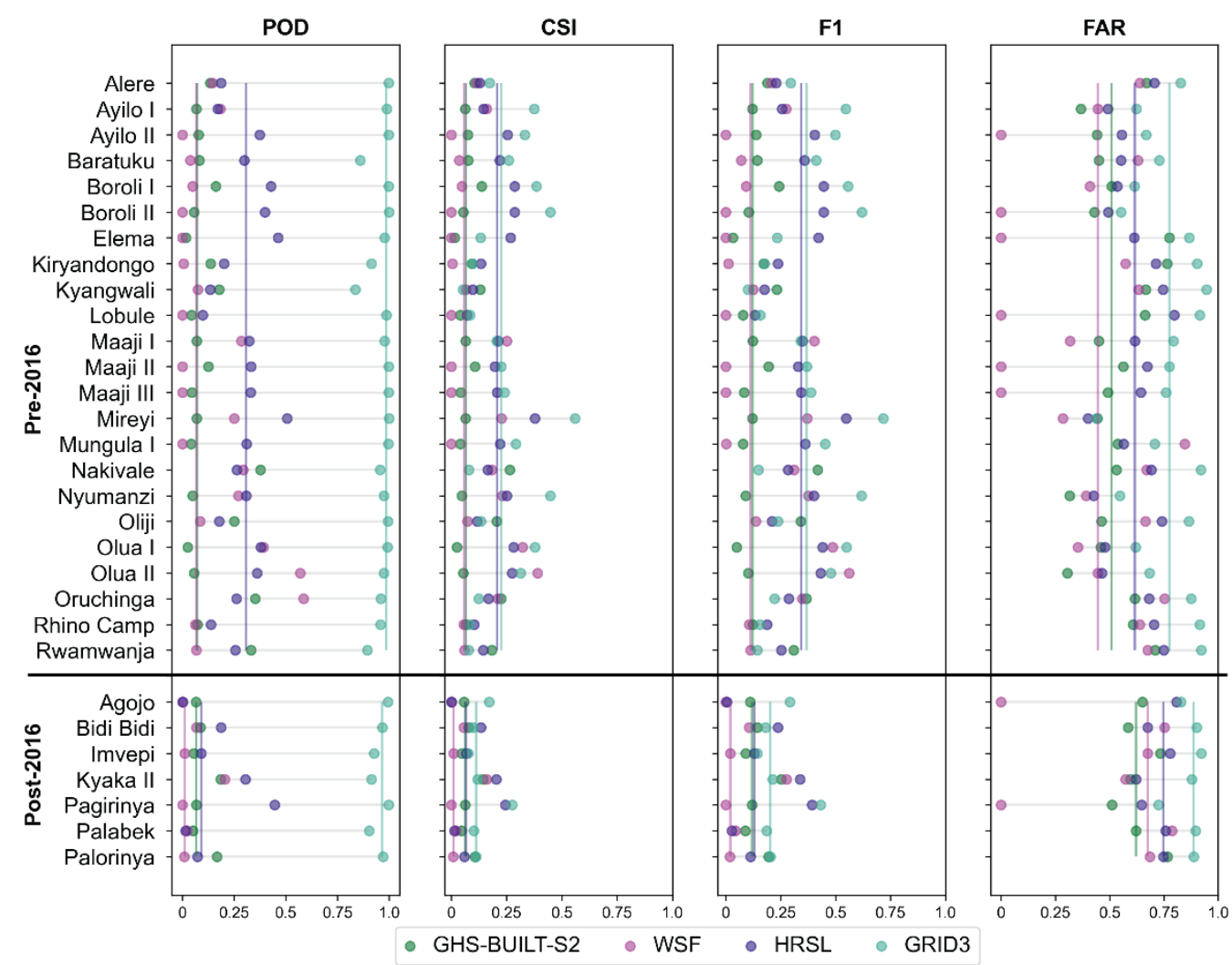

Figure A1. Lollipop plots of Human settlement product validation metrics across all refugee settlements. Vertical colored lines correspond to the median values of each product's relative coverage for pre- and post-2016 settlements. 
S2 True Color

Agojo - 2016

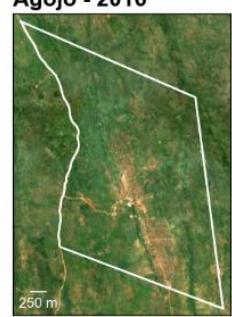

Alere - 2013
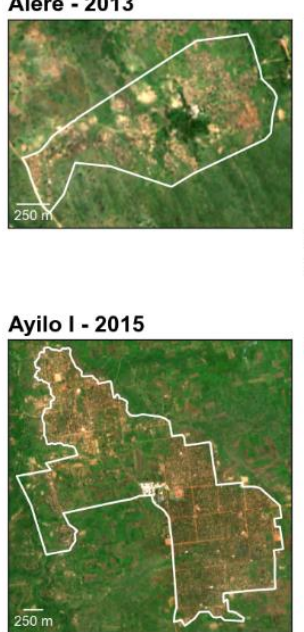

Ayilo II - 2014

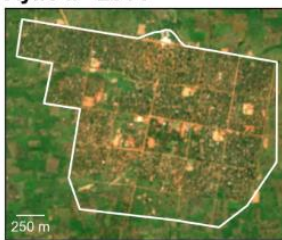

Baratuku - 2013

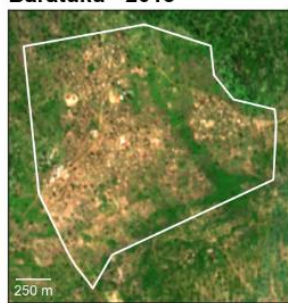

Bidi Bidi - 2016

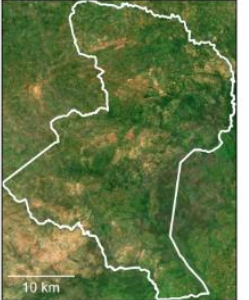

GHS - BUILT - S2

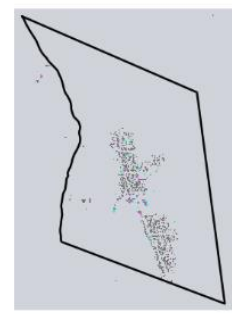

POD: 0.07; CSI: 0.06 F1: 0.11; FAR: 0.65

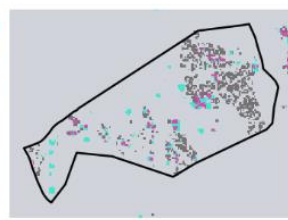

POD: 0.13; CSI: 0.11 F1: 0.19 ; FAR: 0.67

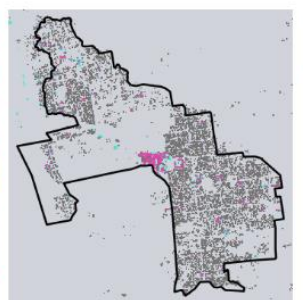
POD: 0.07 ; CSI: 0.06
F1: 0.12 ; FAR: 0.37

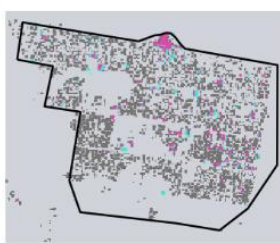

POD: 0.08; CSI: 0.07 F1: 0.14; FAR: 0.44

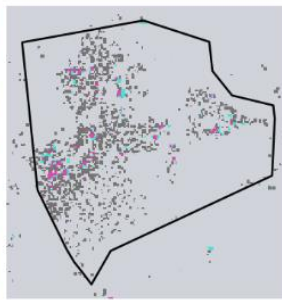

POD: 0.08 ; CSI: 0.08 F1: 0.14; FAR: 0.45

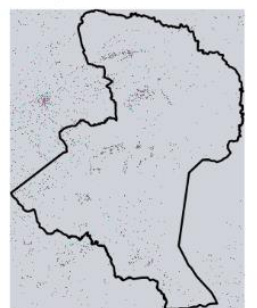

POD: 0.09 ; CSI: 0.08 F1: 0.14 ; FAR: 0.58

$$
\text { Hit Miss }
$$

HRSL

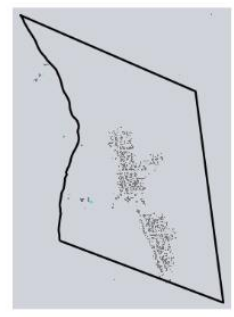

POD: 0.0; CSI: 0.0

POD: 0.0 ; CSI: 0.0
F1: 0.0 ; FAR: 0.81

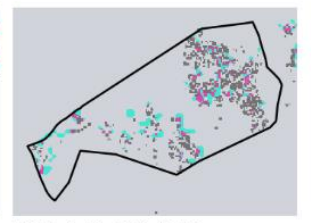

POD: 0.19; CSI: 0.13

F1: 0.23; FAR: 0.71

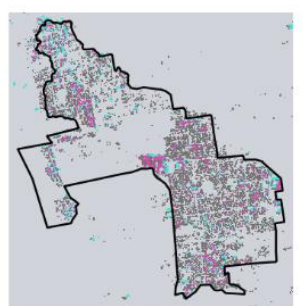

POD: 0.17 ; CSI: 0.15

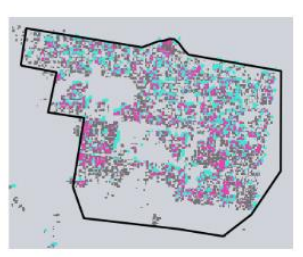

POD: 0.37 ; CSI: 0.25

F1: 0.41; FAR: 0.56

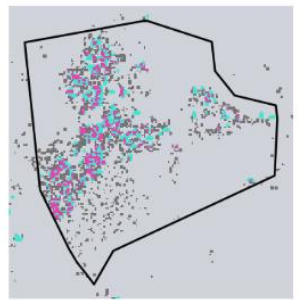

POD: 0.3 ; CSI: 0.22
F1: 0.36 ; FAR: 0.55

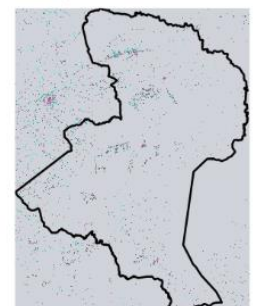

POD: 0.19 ; CSI: 0.14 F1: 0.24 ; FAR: 0.68
WSF

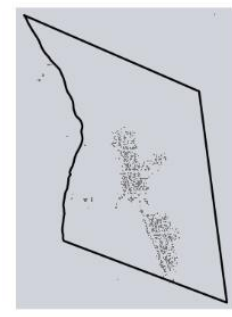

POD: 0.0. CSI: 0.0

F1: 0.0; FAR: 0

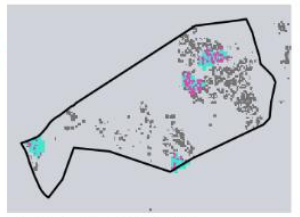

POD: 0.15 ; CSI: 0.12
F1: 0.21 ; FAR: 0.64

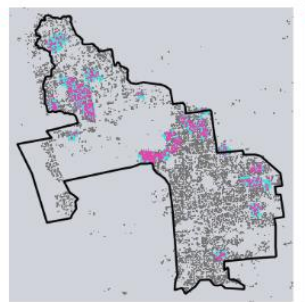

POD: 0.18; CSI: 0.16

F1: 0.27 ; FAR: 0.45

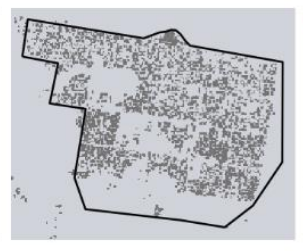

POD: 0.0 ; CSI: 0.0

F1: 0.0; FAR: 0

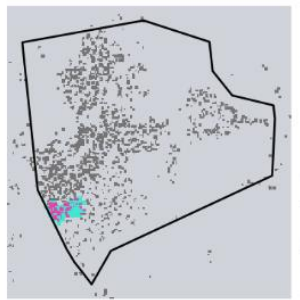

POD: 0.04 ; CSI: 0.04

F1: 0.07 ; FAR: 0.63

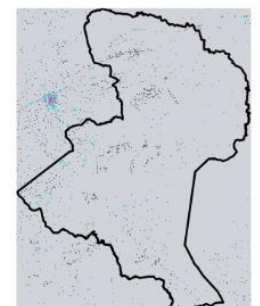

POD: 0.07; CSI: 0.06 F1: 0.11 ; FAR: 0.75

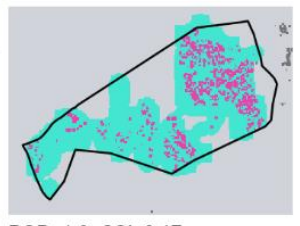

POD: 1.0; CSI: 0.17
F1: 0.3 ; FAR: 0.83

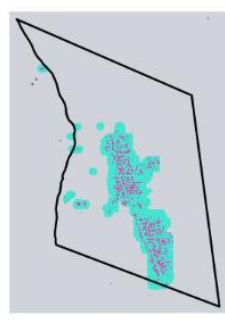

POD: 0.99; CSI: 0.17

F1: 0.29 ; FAR: 0.83

(1)

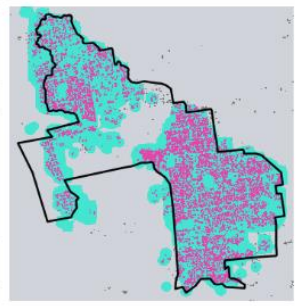

POD: 0.99 ; CSI: 0.38
F1: 0.55 ; FAR: 0.62

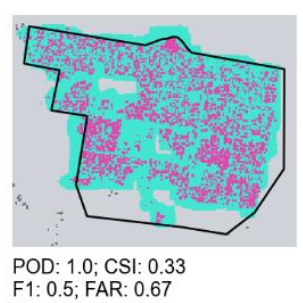

POD: 1.0 ; CSI: 0.33
F1: 0.5 ; FAR: 0.67

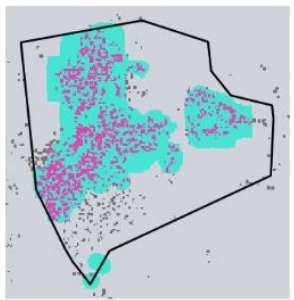

POD: 0.86 ; CSI: 0.26

F1: 0.41 ; FAR: 0.73

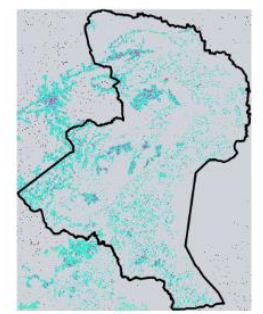

POD: 0.97 ; CSI: 0.1

F1: 0.18 ; FAR: 0.9 


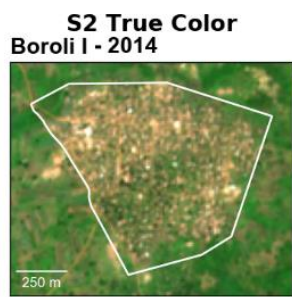

GHS - BUILT - S2

HRSL

WSF

GRID3

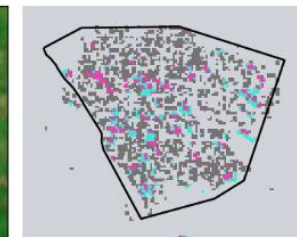

POD: 0.16 . CSI: 0.14 F1: 0.24 ; FAR: 0.51
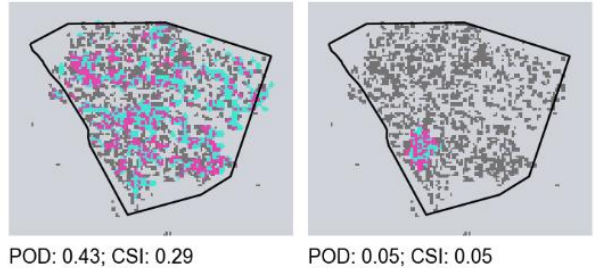

POD: 0.05; CSI: 0.05 F1: 0.45 ; FAR: 0.54

F1: 0.09 ; FAR: 0.41

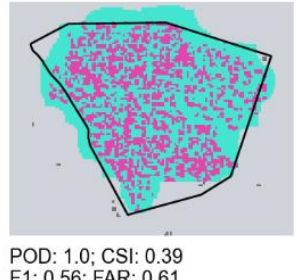

F1: 0.56; FAR: 0.61
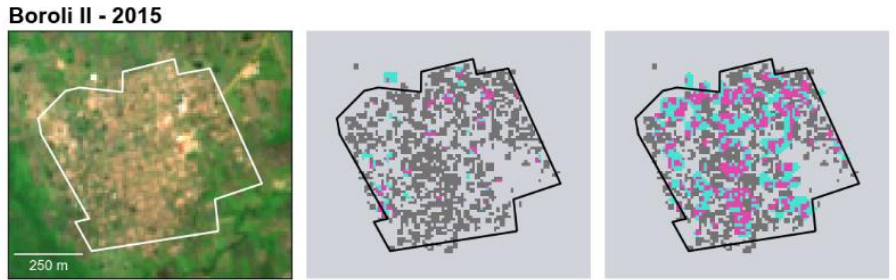

POD: 0.06; CSI: 0.05

POD: 0.4 ; CSI: 0.29

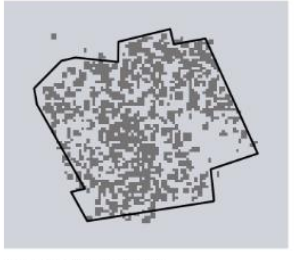

POD: 0.0 ; CSI: 0.0

F1: 0.45 ; FAR: 0.49

F1: 0.0 ; FAR: 0
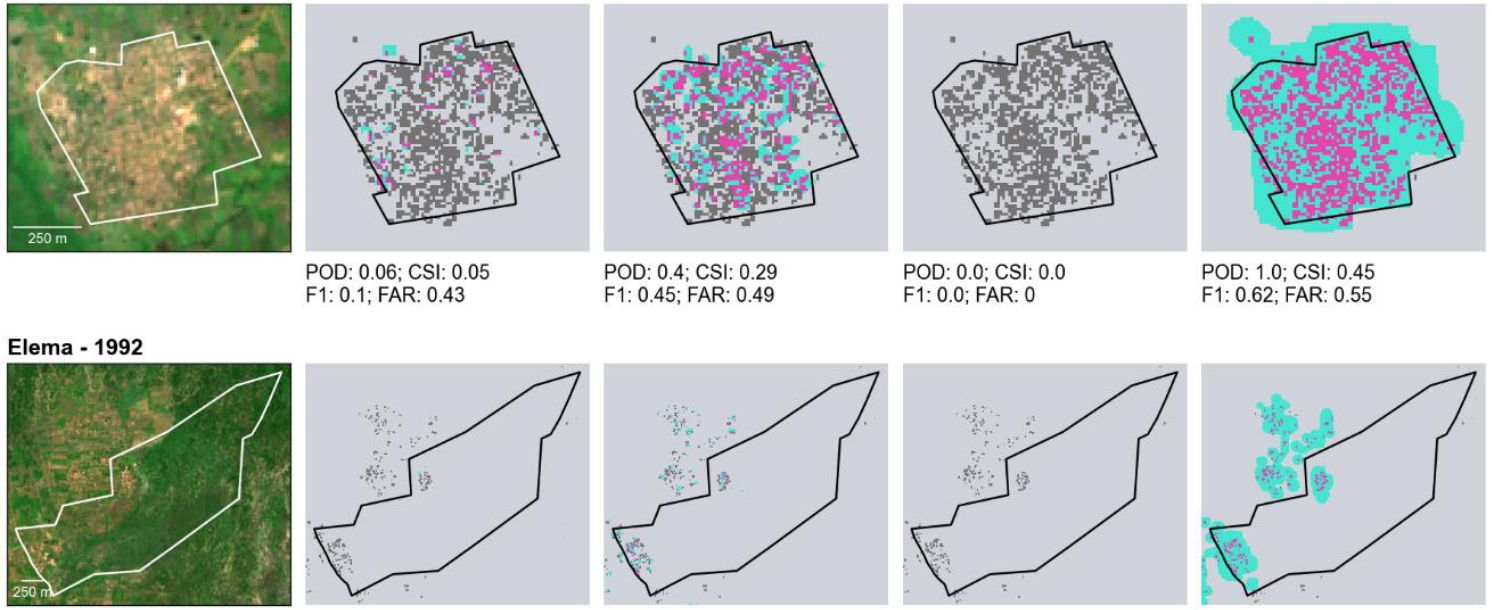

POD: 0.02; CSI: 0.02
F1:003: FAR: 0.77

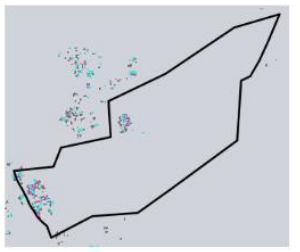

POD: 0.46 ; CSI: 0.27

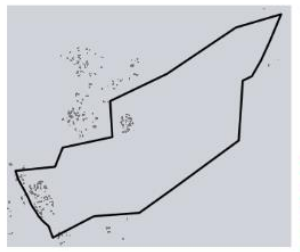

POD: 0.0; CSI: 0.0

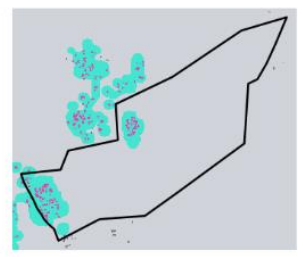

POD: 0.98 ; CSI: 0.13

Imvepi - 2017
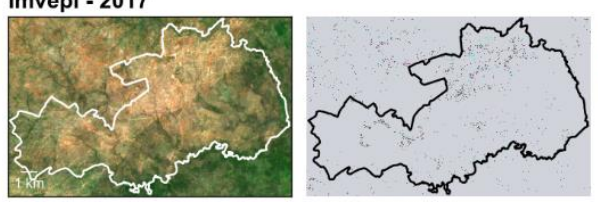

POD: 0.05; CSI: 0.05 F1: 0.09; FAR: 0.73

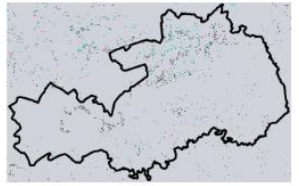
POD: 0.09 ; CSI: 0.07
F1: 0.13; FAR: 0.78

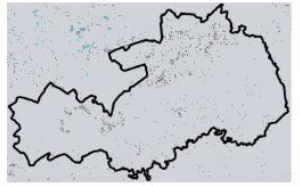

POD: 0.01; CSI: 0.01 F1: 0.02; FAR: 0.68
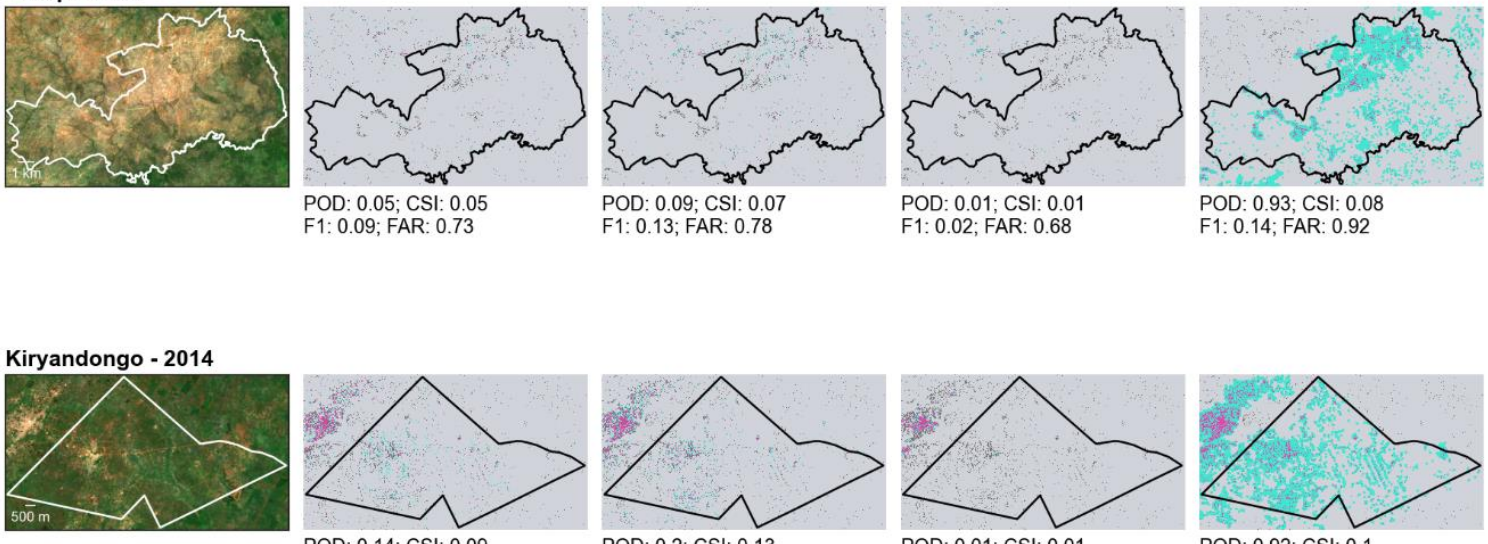

POD: 0.14 ; CSI: 0.0
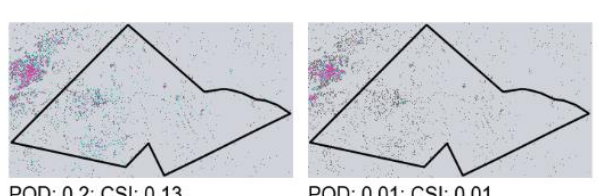

POD: 0.01 ; CSI: 0.01
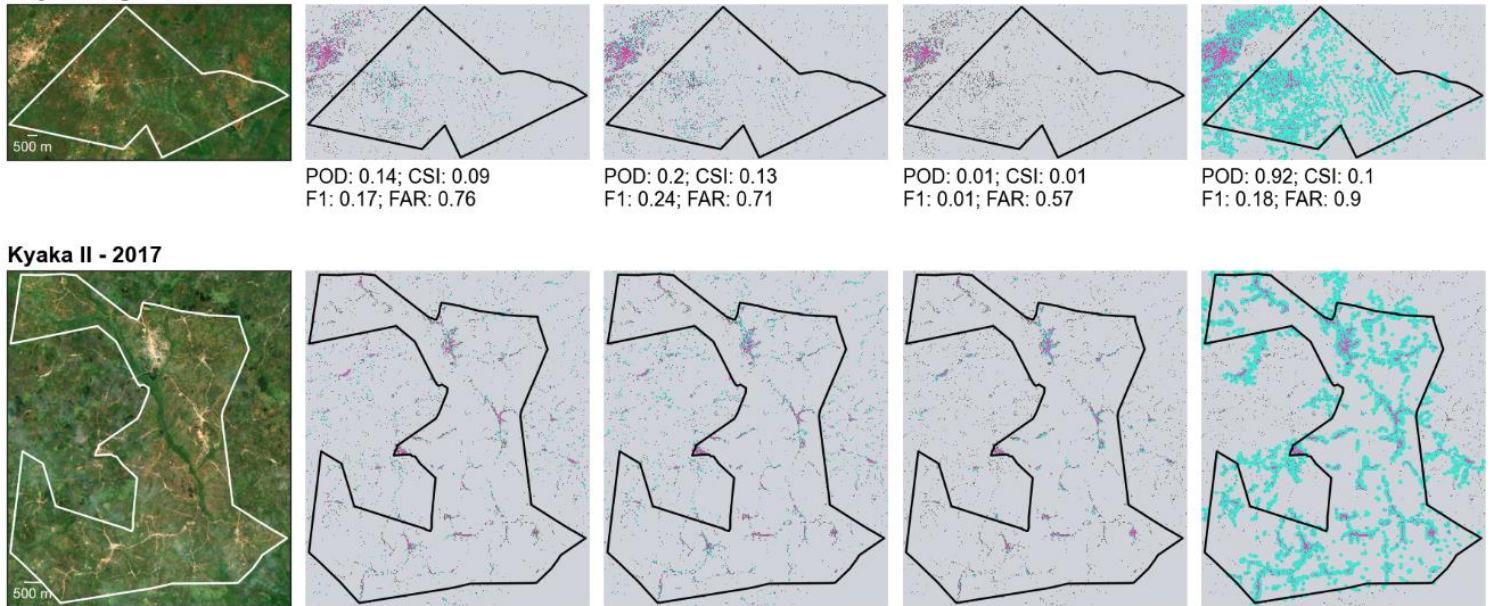

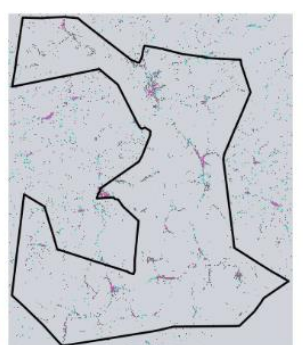

POD: 0.18 ; CSI: 0.15 F1: 0.25; FAR: 0.6
F1: 0.24 ; FAR: 0.71

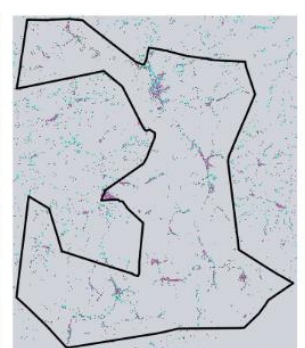

POD: 0.31 ; CSI: 0.2

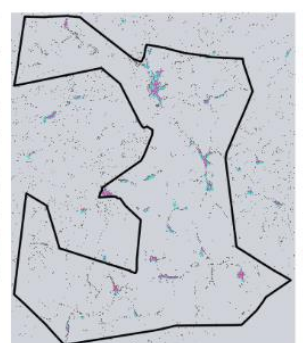

POD: 0.2 ; CSI: 0.16 F1: 0.28; FAR: 0.57

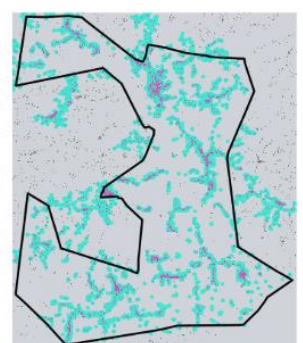

POD: 0.91; CSI: 0.12 F1: 0.21 ; FAR: 0.88

$$
\text { - Hit Miss } \quad \text { False None - Refugee Settlement Boundary }
$$




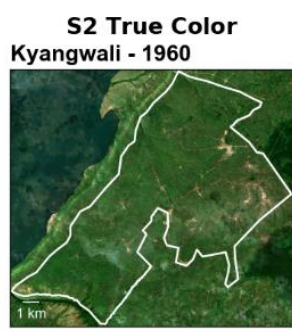

GHS - BUILT - S2

HRSL

WSF

GRID3

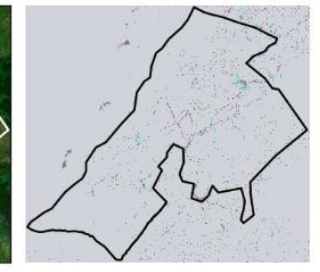

POD: 0.18; CSI: 0.13

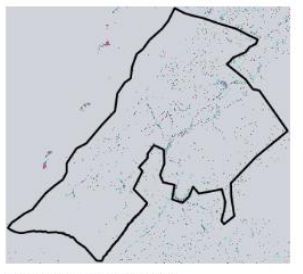

POD: 0.13; CSI: 0.1
F1: 0.18; FAR: 0.75

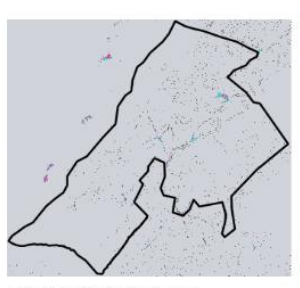

POD: 0.07 ; CSI: 0.07 F1: 0.12 ; FAR: 0.63

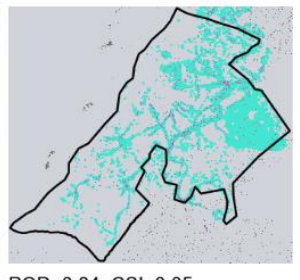
POD: 0.84 ; CSI: 0.05
F1: 0.1 ; FAR: 0.95

Lobule - 2013

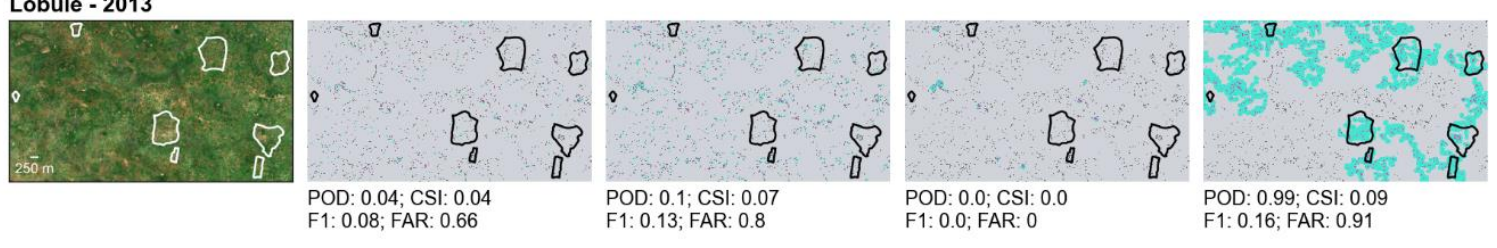

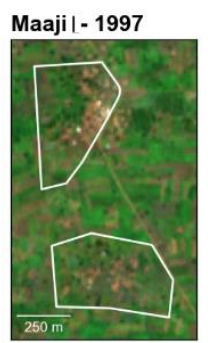

Maaji II - 2015

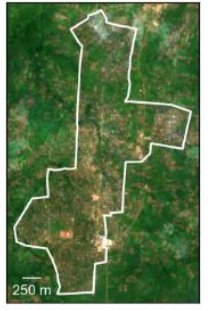

Maaji III- 2015

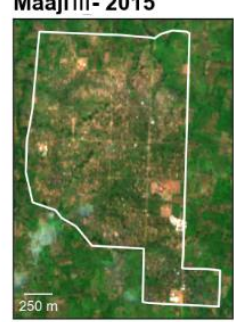

Mireyi - 1994

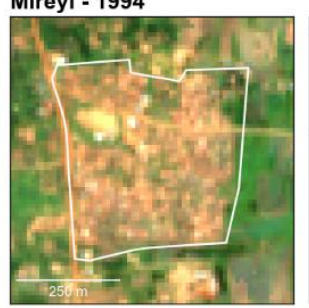

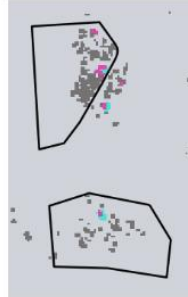

POD: 0.07 ; CSI: 0.07 F1: 0.12 ; FAR: 0.45

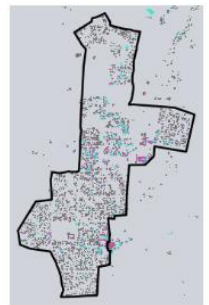

POD: 0.13; CSI: 0.11 F1: 0.19; FAR: 0.56

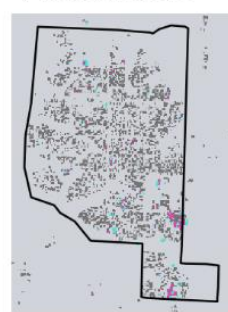

POD: 0.05; CSI: 0.04 F1: 0.08; FAR: 0.49

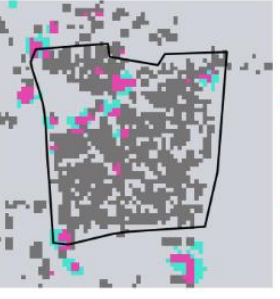

POD: 0.07 ; CSI: 0.06 F1: 0.12; FAR: 0.44

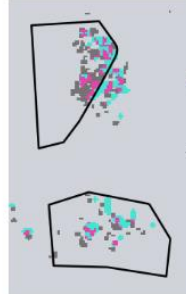

POD: 0.32 ; CSI: 0.21 F1: 0.35 ; FAR: 0.62
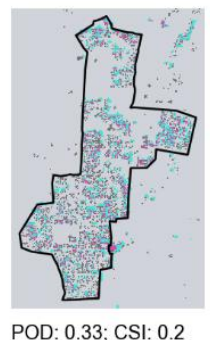

F1: 0.33; FAR: 0.67

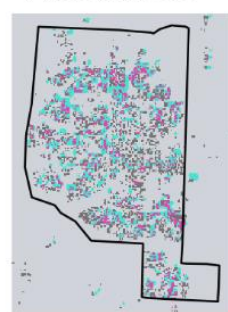

POD: 0.33; CSI: 0.21 F1: 0.34 ; FAR: 0.64

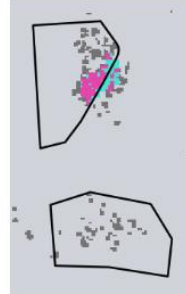

POD: 0.29 ;CS: 0.25 F1: 0.4 ; FAR: 0.32

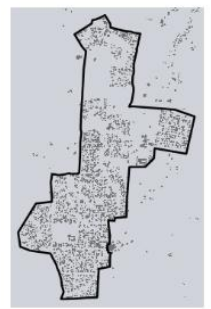

POD: 0.0; CSI: 0.0 F1: 0.0; FAR: 0

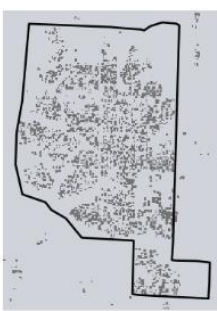

POD: 0.0 ; CSI: 0.0 F1: 0.0; FAR: 0

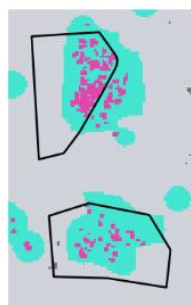

POD: 0.98; CSI: 0.21 F1: 0.34 ; FAR: 0.79

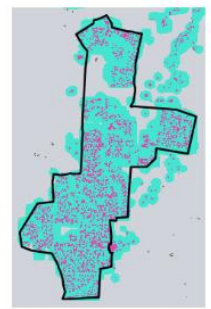

POD: 1.0; CSI: 0.23 F1: 0.37 ; FAR: 0.77

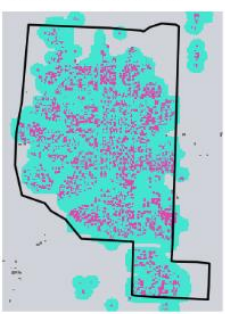

POD: 1.0; CSI: 0.24 F1: 0.39; FAR: 0.76

$$
\text { - Hit Miss False None - Refugee Settlement Boundary }
$$

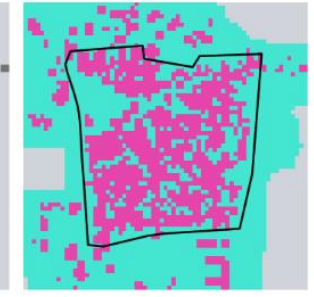

POD: 1.0; CSI: 0.56 F1: 0.72; FAR: 0.44 


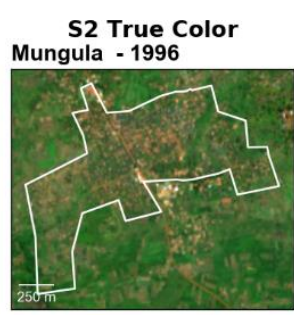

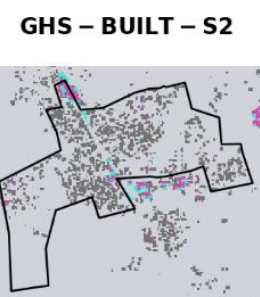

POD: 0.04 ; CSI: 0.04 F1: 0.08; FAR: 0.54
HRSL

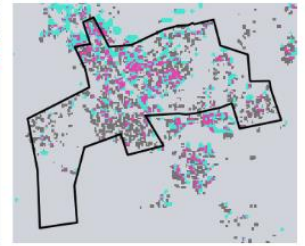

POD: 0.31 ; CSI: 0.22
WSF

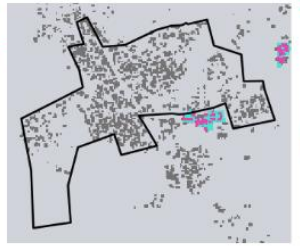

POD: $0.0 ;$ CSI: 0.0
F1: $0.0 ;$ FAR: 0.85
GRID3

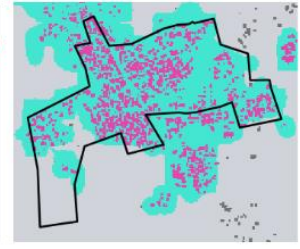

POD: 0.99; CSI: 0.29
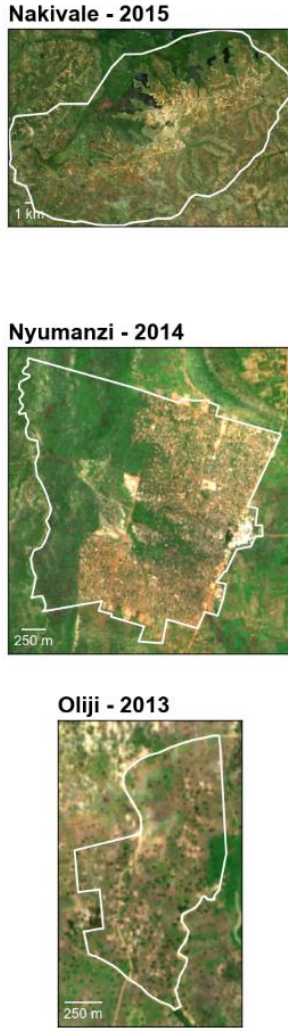

Olua I - 2012
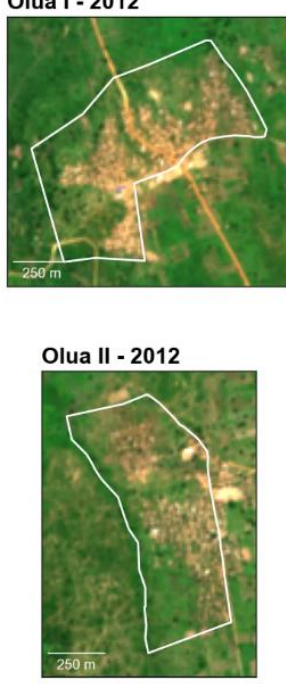

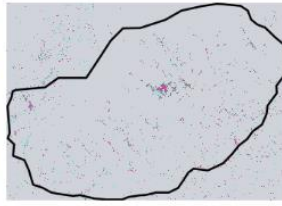

POD: 0.38 ; CSI: 0.26 F1: 0.42; FAR: 0.53

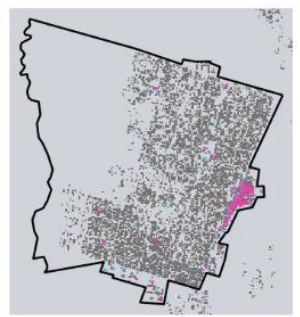

POD: 0.05; CSI: 0.05

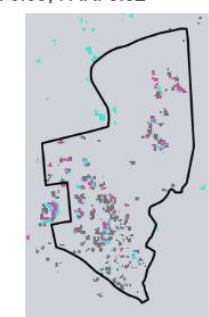

POD: 0.25 ; CSI: 0.21 F1: 0.34 ; FAR: 0.46

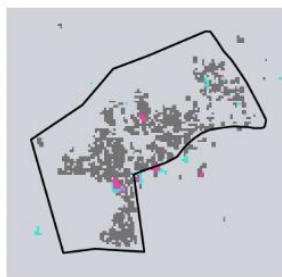

$$
\text { POD: 0.03; CSI: } 0.03
$$
F1: 0.05 ; FAR: 0.46

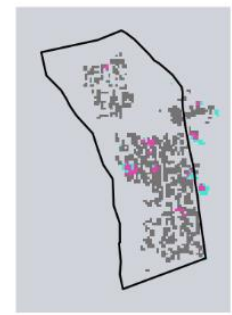

POD: 0.06 ; CSI: 0.05 F1: 0.1 ; FAR: 0.3

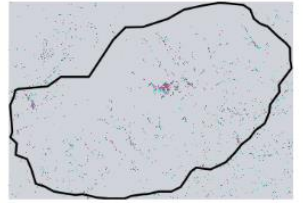

POD: 0.26 . CSI: 0.17 F1: 0.28; FAR: 0.69

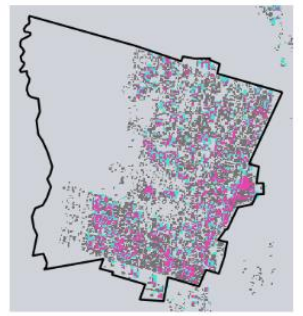

POD: 0.31 ; CSI: 0.25

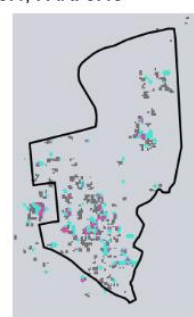

POD: 0.18; CSI: 0.12 F1: 0.21 ; FAR: 0.74

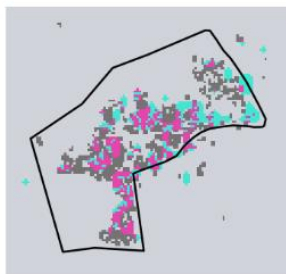

POD: 0.38; CSI: 0.28 F1: 0.44 ; FAR: 0.48

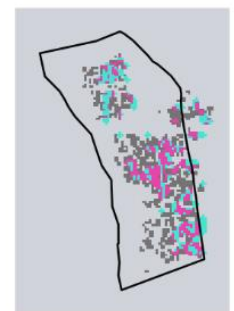

POD: 0.36 ; CSI: 0.28 F1: 0.43 ; FAR: 0.46

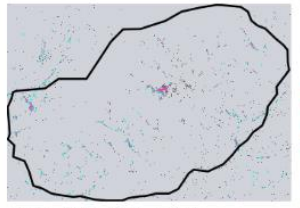

POD: 0.29; CSI: 0.18 F1: 0.31; FAR: 0.67

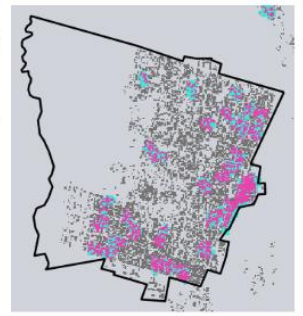

POD: 0.27 ; CSI: 0.23

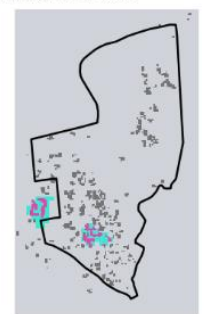

POD: 0.09 ; CSI: 0.07 F1: 0.14 ; FAR: 0.66

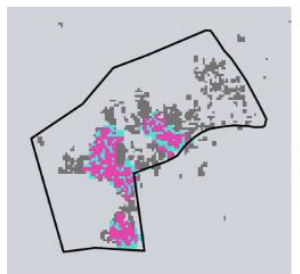

POD: 0.39 ; CSI: 0.32 F1: 0.49 ; FAR: 0.35

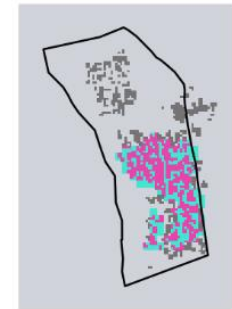

POD: 0.57; CSI: 0.39 F1: 0.56; FAR: 0.45

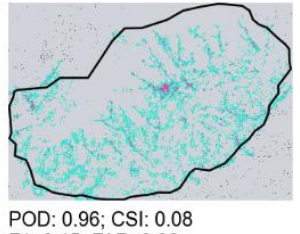

F1: 0.15. FAR:

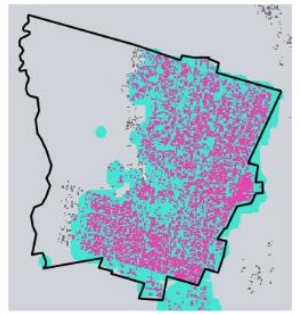

POD: 0.97; CSI: 0.45 F1: 0.62; FAR: 0.55

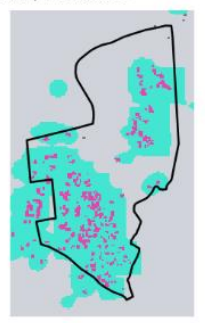

POD: 0.99; CSI: 0.13 F1: 0.24 ; FAR: 0.87

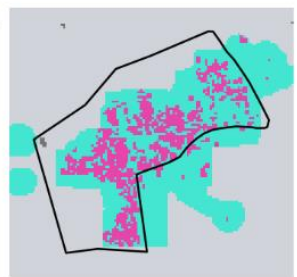

POD: 0.99; CSI: 0.38

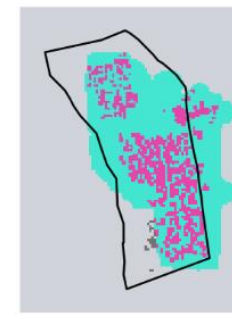

POD: 0.97: CSI: 0.31 F1: 0.48 ; FAR: 0.68 

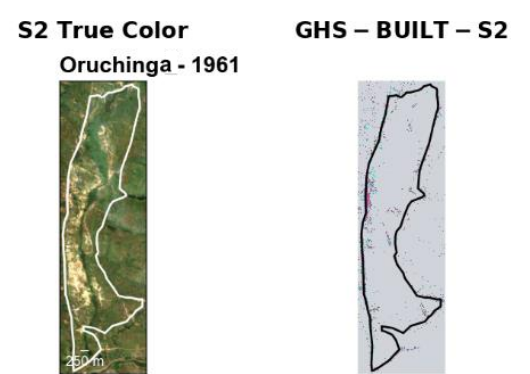

Pagirinya - 2016

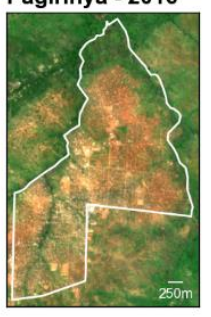

POD: 0.35; CSI: 0.23 F1: 0.37 ; FAR: 0.62

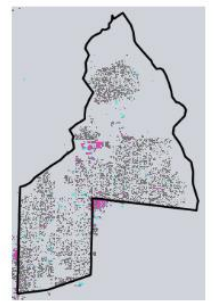

POD: 0.07; CSI: 0.06 F1: 0.12; FAR: 0.51
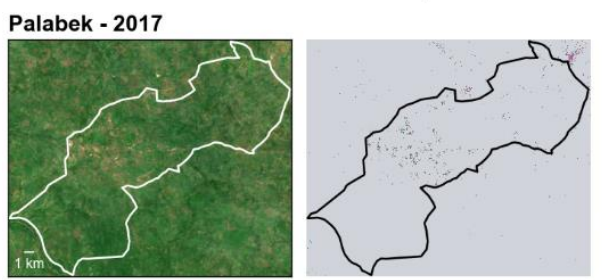
POD: 0.05 ; CSI: 0.05
F1: 0.09 ; FAR: 0.62

HRSL

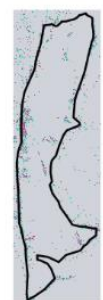
POD: 0.26 ; CSI: 0.17
F1: 0.29 ; FAR: 0.68

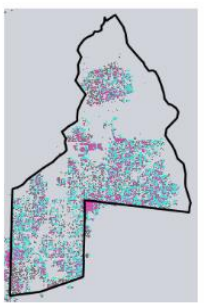

POD: 0.45 ; CSI: 0.24 F1: 0.39 ; FAR: 0.65

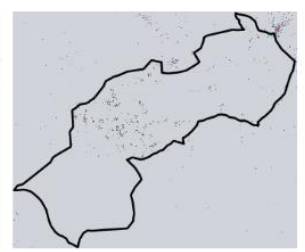

POD: 0.01; CSI: 0.01 F1: 0.03 ; FAR: 0.76
WSF

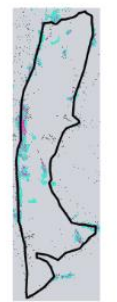
POD: 0.59; CSI: 0.21
F1: 0.35 ; FAR: 0.75

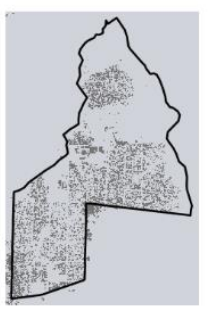

POD: 0.0; CSI: 0.0 F1: 0.0; FAR: 0

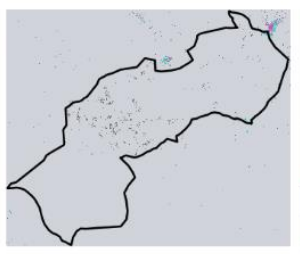

POD: 0.02; CSI: 0.02 F1: 0.04;FAR: 0.79
GRID3

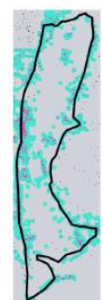

POD: 0.96; CSI: 0.13 F1: 0.22 ; FAR: 0.87

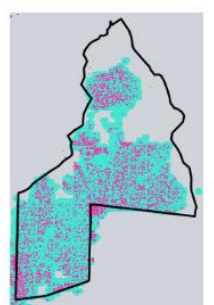
POD: 1.0 ; CSI: 0.28
F1: 0.43 ; FAR: 0.72

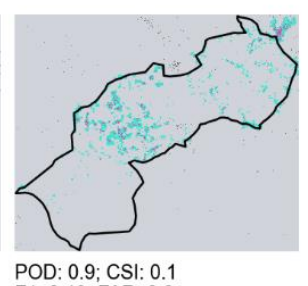
POD: 0.9; CSI: 0.1
F1: 0.19; FAR: 0.9
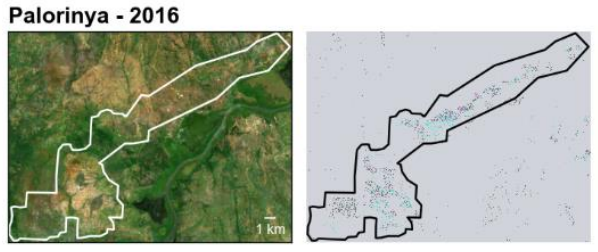
POD: 0.17; CSI: 0.1

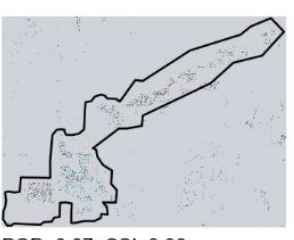
POD: 0.07 ; CSI: 0.06 F1: 0.11; FAR: 0.75

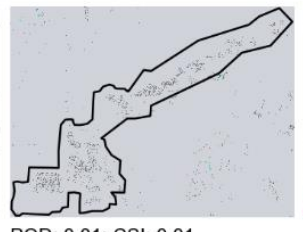

POD: 0.01 ; CSI: 0.01

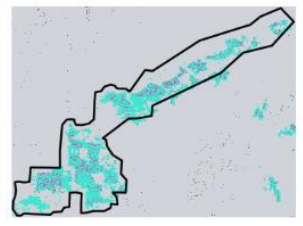

POD: 0.97; CSI: 0.11
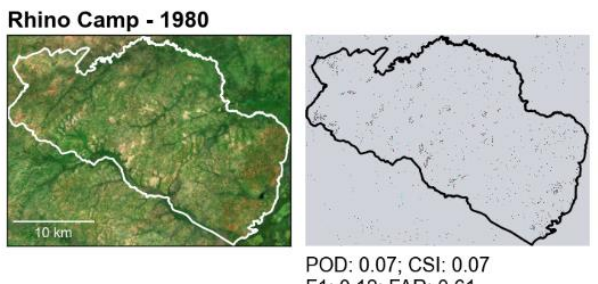
F1: 0.12 ; FAR: 0.61

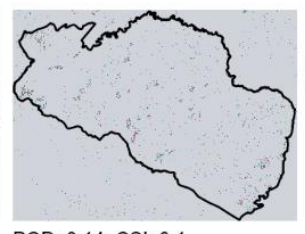

POD: 0.14 ; CSI: 0.1

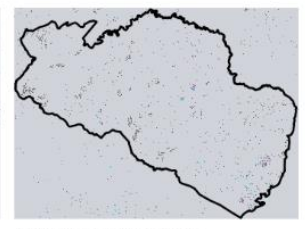

POD: 0.06 ; CSI: 0.06 F1: 0.11 ; FAR: 0.64

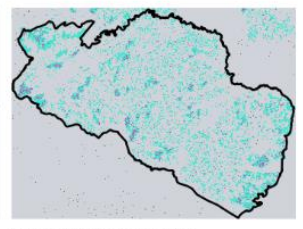

POD: 0.96; CSI: 0.08

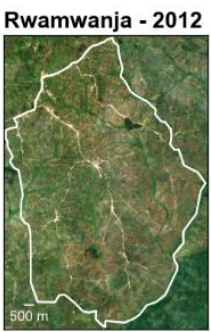

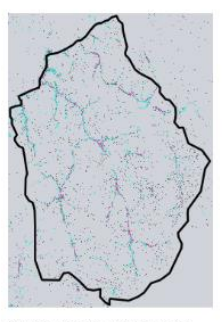

POD: 0.33 ; CSI: 0.18

- Hit Miss

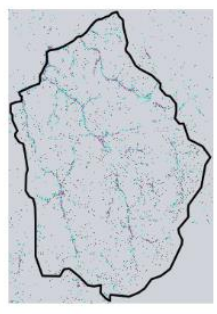

POD: 0.26; CSI: 0.14 F1: 0.25 ; FAR: 0.75

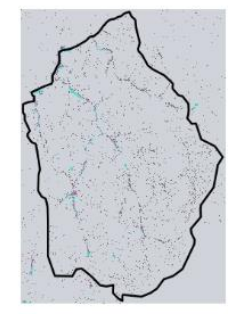

POD: 0.07; CSI: 0.06 F1: 0.11; FAR: 0.67

$$
\text { False None - Refugee Settlement Boundary }
$$

Figure A2. Settlement-level validation maps and validation metrics for all four settlement products. Validation metrics are evaluated relative to OSM-MS building footprint coverage within settlement boundaries. 
Agojo - 2016

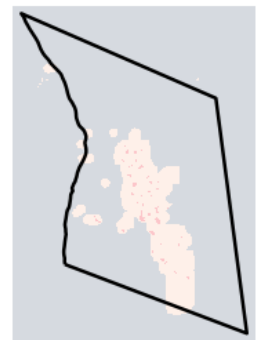

Ayilo II - 2014

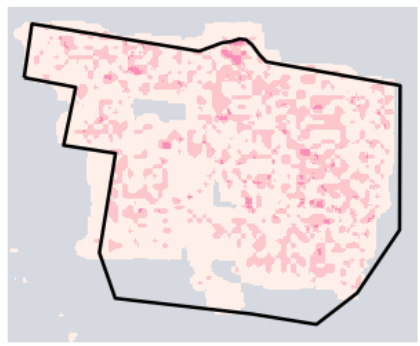

Boroli I - 2014

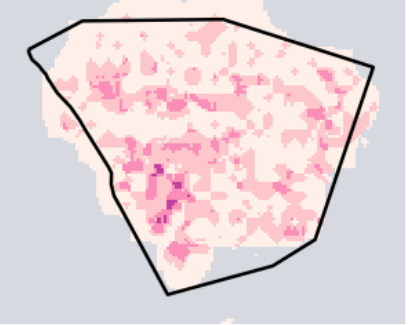

Imvepi - 2017

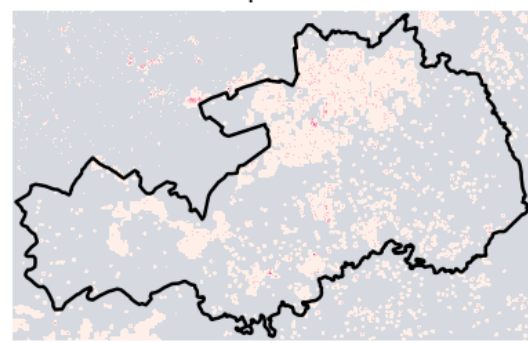

Kyangwali - 1960

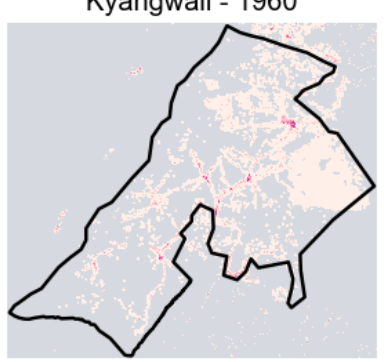

1 product

2 products
Alere - 2013

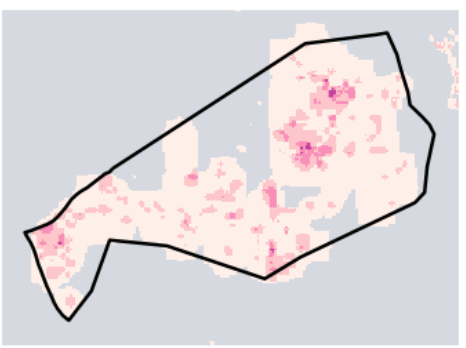

Baratuku - 2013

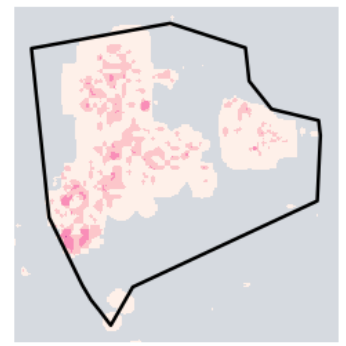

Boroli II - 2015
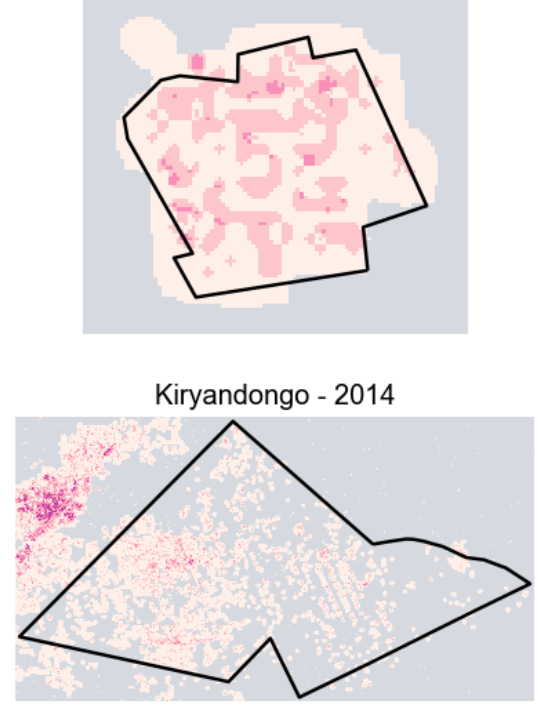

Lobule - 2013

8

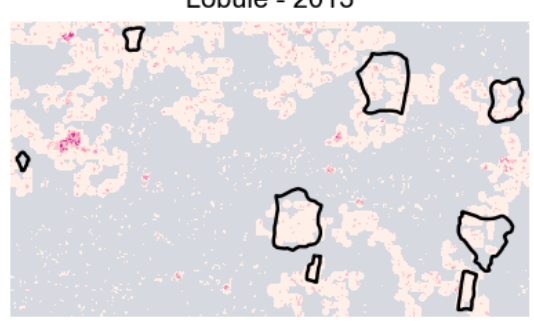

0

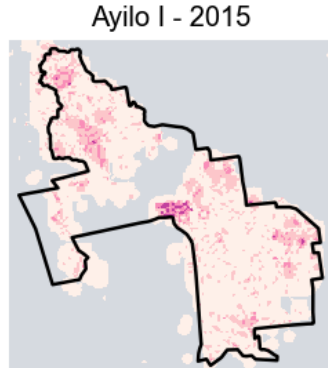

Bidi Bidi - 2016

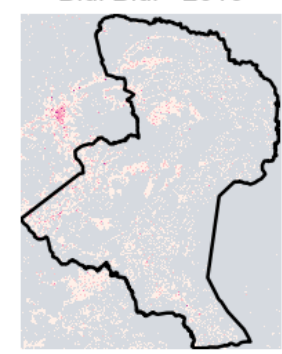

Elema - 1992

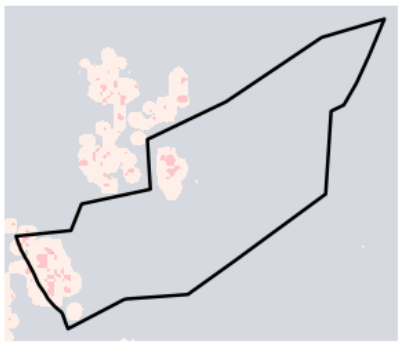

Kyaka II - 2017

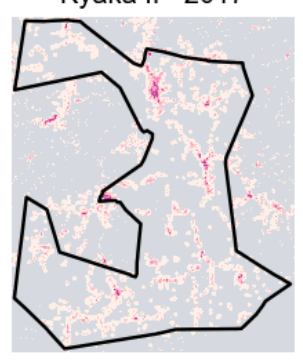

Maaji I - 1997

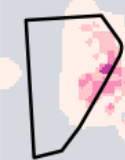

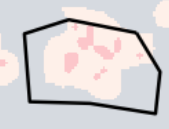

3 products None

4 products - Refugee Settlement Boundary 


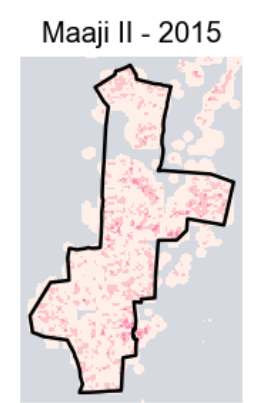

Mungula I - 1996

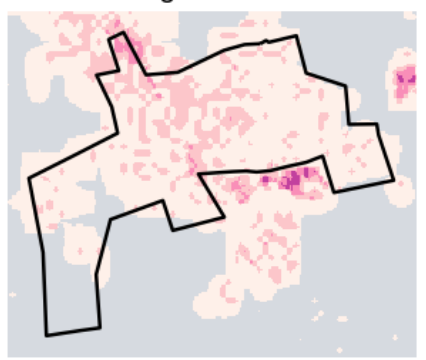

Oliji - 2013

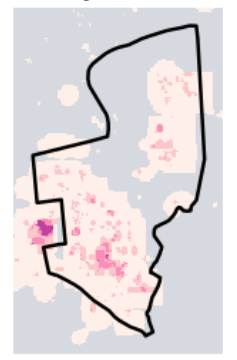

Oruchinga - 1961

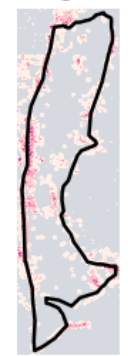

Palorinya - 2016

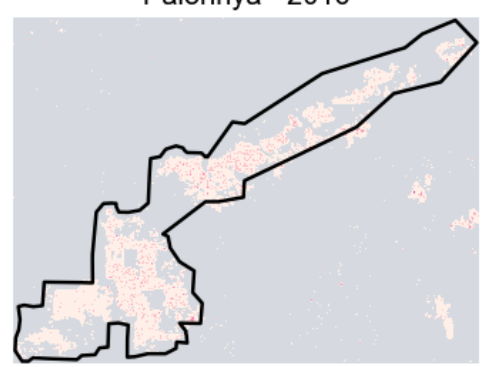

1 product

2 products
Maaji III - 2015

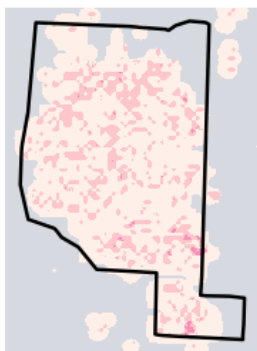

Nakivale - 2015

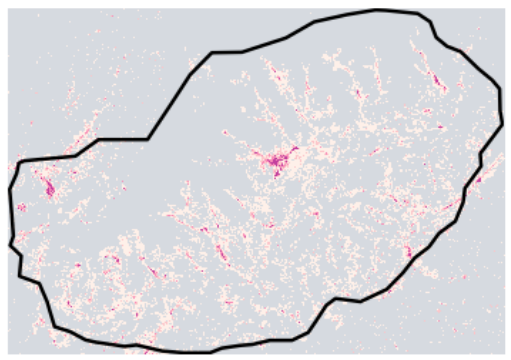

Olua I - 2012

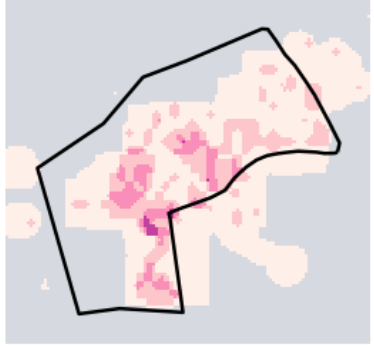

Pagirinya - 2016

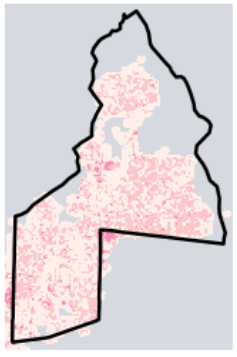

Rhino Camp - 1980

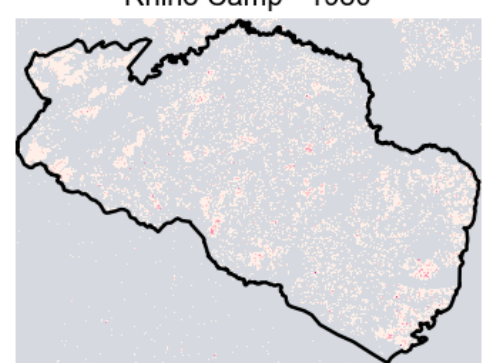

3 products

4 products

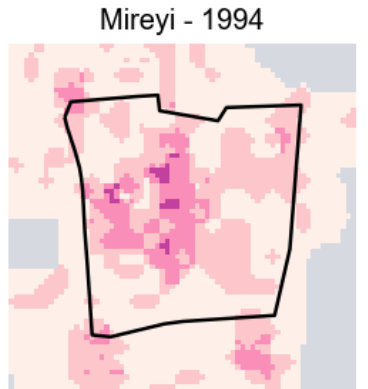

Nyumanzi - 2014

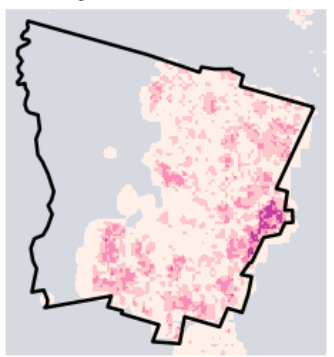

Olua II - 2012

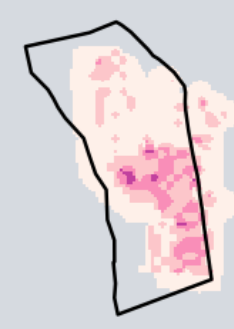

Palabek - 2017

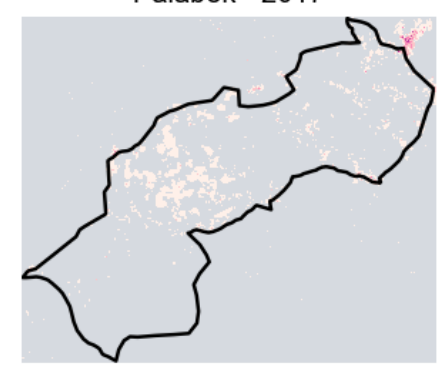

Rwamwanja - 2012

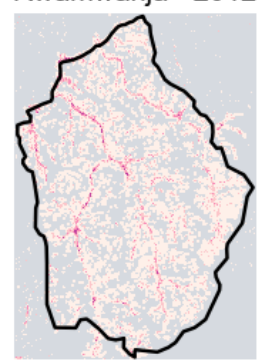

Figure A3. Maps of agreement between four settlement products at refugee settlements. " 1 product" indicates unique coverage by a single product. " 2 products", "3 products", and " 4 products" indicate the number of settlement products that share coverage. "None" indicates zero coverage. Note that the spatial scale of settlement maps varies. 


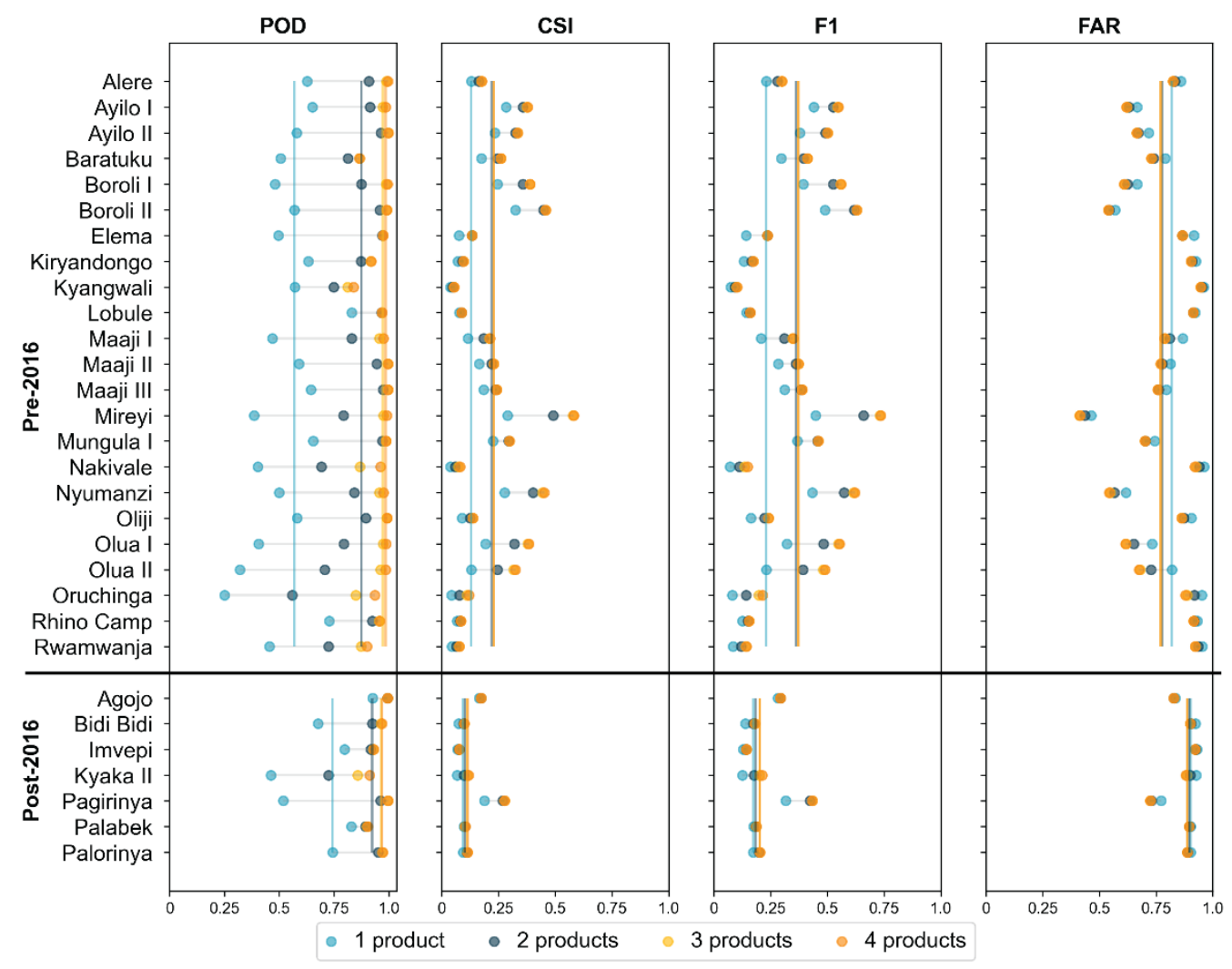

Figure A4. Lollipop plots of Probability of Detection (POD), Critical Success Index (CSI), F1-Score (F1), and False Alarm Rate (FAR) for multi-product agreement sites in comparison to OSM-MS building footprint coverage across all refugee settlements. "1 product" indicates unique coverage by a single product. " 2 products", "3 products", and " 4 products" indicate the number of settlement products that share coverage.

\section{References}

1. Pesaresi, M.; Huadong, G.; Blaes, X.; Ehrlich, D.; Ferri, S.; Gueguen, L.; Halkia, M.; Kauffmann, M.; Kemper, T.; Lu, L.; et al. A Global Human Settlement Layer From Optical HR/VHR RS Data: Concept and First Results. IEEE J. Sel. Top. Appl. Earth Obs. Remote Sens. 2013, 6, 2102-2131, doi:10.1109/JSTARS.2013.2271445.

2. Corbane, C.; Syrris, V.; Sabo, F.; Politis, P.; Melchiorri, M.; Pesaresi, M.; Soille, P.; Kemper, T. Convolutional Neural Networks for Global Human Settlements Mapping from Sentinel-2 Satellite Imagery. Neural Comput. Appl. 2021, 33, 6697-6720, doi:10.1007/s00521-020-05449-7.

3. Marconcini, M.; Metz-Marconcini, A.; Üreyen, S.; Palacios-Lopez, D.; Hanke, W.; Bachofer, F.; Zeidler, J.; Esch, T.; Gorelick, N.; Kakarla, A.; et al. Outlining Where Humans Live, the World Settlement Footprint 2015. Sci. Data 2020, 7, 242, doi:10.1038/s41597-020-00580-5.

4. Facebook Connectivity Lab; CIESIN High Resolution Settlement Layer Available online: https://ciesin.columbia.edu/data/hrsl/ (accessed on 5 July 2021).

5. CIESIN; Flowminder Foundation; UN Population Fund; WorldPop, University of Southampton Mapping and Classifying Settlement Locations; 2020.

6. Klotz, M.; Kemper, T.; Geiß, C.; Esch, T.; Taubenböck, H. How Good Is the Map? A Multi-Scale Cross-Comparison Framework for Global Settlement Layers: Evidence from Central Europe. Remote Sens. Environ. 2016, 178, 191-212, doi:10.1016/j.rse.2016.03.001. 
7. Corbane, C.; Pesaresi, M.; Kemper, T.; Politis, P.; Florczyk, A.J.; Syrris, V.; Melchiorri, M.; Sabo, F.; Soille, P. Automated Global Delineation of Human Settlements from 40 Years of Landsat Satellite Data Archives. Big Earth Data 2019, 3, 140-169, doi:10.1080/20964471.2019.1625528.

8. Melchiorri, M.; Florczyk, A.J.; Freire, S.; Schiavina, M.; Pesaresi, M.; Kemper, T. Unveiling 25 Years of Planetary Urbanization with Remote Sensing: Perspectives from the Global Human Settlement Layer. Remote Sens. 2018, 10, 768, doi:10.3390/rs10050768.

9. Esch, T.; Bachofer, F.; Heldens, W.; Hirner, A.; Marconcini, M.; Palacios-Lopez, D.; Roth, A.; Üreyen, S.; Zeidler, J.; Dech, S.; et al. Where We Live-A Summary of the Achievements and Planned Evolution of the Global Urban Footprint. Remote Sens. 2018, 10, 895, doi:10.3390/rs10060895.

10. Leyk, S.; Gaughan, A.E.; Adamo, S.B.; de Sherbinin, A.; Balk, D.; Freire, S.; Rose, A.; Stevens, F.R.; Blankespoor, B.; Frye, C.; et al. The Spatial Allocation of Population: A Review of Large-Scale Gridded Population Data Products and Their Fitness for Use. Earth Syst. Sci. Data 2019, 11, 1385-1409, doi:10.5194/essd-11-1385-2019.

11. Lloyd, C.T.; Sorichetta, A.; Tatem, A.J. High Resolution Global Gridded Data for Use in Population Studies. Sci. Data 2017, 4, 170001, doi:10.1038/sdata.2017.1.

12. Lloyd, C.T.; Chamberlain, H.; Kerr, D.; Yetman, G.; Pistolesi, L.; Stevens, F.R.; Gaughan, A.E.; Nieves, J.J.; Hornby, G.; MacManus, K.; et al. Global Spatio-Temporally Harmonised Datasets for Producing High-Resolution Gridded Population Distribution Datasets. Big Earth Data 2019, 3, 108-139, doi:10.1080/20964471.2019.1625151.

13. Freire, S.; Schiavina, M.; Florczyk, A.J.; MacManus, K.; Pesaresi, M.; Corbane, C.; Borkovska, O.; Mills, J.; Pistolesi, L.; Squires, J.; et al. Enhanced Data and Methods for Improving Open and Free Global Population Grids: Putting ‘Leaving No One behind' into Practice. Int. J. Digit. Earth 2020, 13, 61-77, doi:10.1080/17538947.2018.1548656.

14. Palacios-Lopez, D.; Bachofer, F.; Esch, T.; Marconcini, M.; MacManus, K.; Sorichetta, A.; Zeidler, J.; Dech, S.; Tatem, A.J.; Reinartz, P. High-Resolution Gridded Population Datasets: Exploring the Capabilities of the World Settlement Footprint 2019 Imperviousness Layer for the African Continent. Remote Sens. 2021, 13, 1142, doi:10.3390/rs13061142.

15. Melchiorri, M.; Pesaresi, M.; Florczyk, A.J.; Corbane, C.; Kemper, T. Principles and Applications of the Global Human Settlement Layer as Baseline for the Land Use Efficiency Indicator-SDG 11.3.1. ISPRS Int. J. Geo-Inf. 2019, 8, 96, doi:10.3390/ijgi8020096.

16. Aguilar, R.; Kuffer, M. Cloud Computation Using High-Resolution Images for Improving the SDG Indicator on Open Spaces. Remote Sens. 2020, 12, 1144, doi:10.3390/rs12071144.

17. Corbane, C.; Martino, P.; Panagiotis, P.; Aneta, F.J.; Michele, M.; Sergio, F.; Marcello, S.; Daniele, E.; Gustavo, N.; Thomas, K. The Grey-Green Divide: Multi-Temporal Analysis of Greenness across 10,000 Urban Centres Derived from the Global Human Settlement Layer (GHSL). Int. J. Digit. Earth 2020, 13, 101-118, doi:10.1080/17538947.2018.1530311.

18. Ehrlich, D.; Kemper, T.; Pesaresi, M.; Corbane, C. Built-up Area and Population Density: Two Essential Societal Variables to Address Climate Hazard Impact. Environ. Sci. Policy 2018, 90, 73-82.

19. Formetta, G.; Feyen, L. Empirical Evidence of Declining Global Vulnerability to Climate-Related Hazards. Glob. Environ. Change 2019, 57, 101920, doi:10.1016/j.gloenvcha.2019.05.004.

20. Mazzoleni, M.; Mård, J.; Rusca, M.; Odongo, V.; Lindersson, S.; Baldassarre, G.D. Floodplains in the Anthropocene: A Global Analysis of the Interplay Between Human Population, Built Environment, and Flood Severity. Water Resour. Res. 2021, 57, e2020WR027744, doi:10.1029/2020WR027744.

21. Pesaresi, M.; Ehrlich, D.; Ferri, S.; Florczyk, A.; Freire, S.; Haag, F.; Halkia, M.; Julea, A.M.; Kemper, T.; Soille, P. Global Human Settlement Analysis for Disaster Risk Reduction. Int. Arch. Photogramm. Remote Sens. Spat. Inf. Sci. 2015, XL-7/W3, 837843, doi:10.5194/isprsarchives-XL-7-W3-837-2015.

22. Sabo, F.; Corbane, C.; Florczyk, A.J.; Ferri, S.; Pesaresi, M.; Kemper, T. Comparison of Built-up Area Maps Produced within the Global Human Settlement Framework. Trans. GIS 2018, 22, 1406-1436, doi:10.1111/tgis.12480. 
23. Gerten, C.; Fina, S.; Rusche, K. The Sprawling Planet: Simplifying the Measurement of Global Urbanization Trends. Front. Environ. Sci. 2019, 7, doi:10.3389/fenvs.2019.00140.

24. Mück, M.; Klotz, M.; Taubenböck, H. Validation of the DLR Global Urban Footprint in Rural Areas: A Case Study for Burkina Faso. In Proceedings of the 2017 Joint Urban Remote Sensing Event (JURSE); March 2017; pp. 1-4.

25. Li, J.; Zhang, H.; Wang, C.; Wu, F.; Li, L. Spaceborne SAR Data for Regional Urban Mapping Using a Robust Building Extractor. Remote Sens. 2020, 12, 2791, doi:10.3390/rs12172791.

26. United Nations Department of Economic and Social Affairs, Population Division World Urbanization Prospects: The 2018 Revision (ST/ESA/SER.A/420); United Nations: New York, 2019;

27. UNHCR Global Trends: Forced Displacement in 20202021.

28. Devictor, X.; Do, Q.-T. How Many Years Have Refugees Been in Exile? Popul. Dev. Rev. 2017, 43, 355-369, doi:https://doi.org/10.1111/padr.12061.

29. UNHCR Protracted Refugee Situations 2004.

30. Van Den Hoek, J.; Friedrich, H.K.; Ballasiotes, A.; Peters, L.E.R.; Wrathall, D. Development after Displacement: Evaluating the Utility of OpenStreetMap Data for Monitoring Sustainable Development Goal Progress in Refugee Settlements. ISPRS Int. J. Geo-Inf. 2021, 10, 153, doi:10.3390/ijgi10030153.

31. Aravena Pelizari, P.; Spröhnle, K.; Geiß, C.; Schoepfer, E.; Plank, S.; Taubenböck, H. Multi-Sensor Feature Fusion for Very High Spatial Resolution Built-up Area Extraction in Temporary Settlements. Remote Sens. Environ. 2018, 209, 793-807, doi:10.1016/j.rse.2018.02.025.

32. Jenerowicz, M.; Wawrzaszek, A.; Drzewiecki, W.; Krupiński, M.; Aleksandrowicz, S. Multifractality in Humanitarian Applications: A Case Study of Internally Displaced Persons/Refugee Camps. IEEE J. Sel. Top. Appl. Earth Obs. Remote Sens. 2019, 12, 4438-4445, doi:10.1109/JSTARS.2019.2950970.

33. Spröhnle, K.; Tiede, D.; Schoepfer, E.; Füreder, P.; Svanberg, A.; Rost, T. Earth Observation-Based Dwelling Detection Approaches in a Highly Complex Refugee Camp Environment - A Comparative Study. Remote Sens. 2014, 6, 9277-9297, doi:10.3390/rs6109277.

34. Ghorbanzadeh, O.; Tiede, D.; Wendt, L.; Sudmanns, M.; Lang, S. Transferable Instance Segmentation of Dwellings in a Refugee Camp - Integrating CNN and OBIA. Eur. J. Remote Sens. 2021, 54, 127-140, doi:10.1080/22797254.2020.1759456.

35. Tiede, D.; Krafft, P.; Füreder, P.; Lang, S. Stratified Template Matching to Support Refugee Camp Analysis in OBIA Workflows. Remote Sens. 2017, 9, 326, doi:10.3390/rs9040326.

36. Tiede, D.; Schwendemann, G.; Alobaidi, A.; Wendt, L.; Lang, S. Mask R-CNN-Based Building Extraction from VHR Satellite Data in Operational Humanitarian Action: An Example Related to Covid-19 Response in Khartoum, Sudan. Trans. GIS 2021, n/a, doi:https://doi.org/10.1111/tgis.12766.

37. Ghorbanzadeh, O.; Tiede, D.; Dabiri, Z.; Sudmanns, M.; Lang, S. DWELLING EXTRACTION IN REFUGEE CAMPS USING CNN-FIRST EXPERIENCES AND LESSONS LEARNT. Int. Arch. Photogramm. Remote Sens. Spat. Inf. Sci. 2018.

38. Green, B.; Blanford, J. Refugee Camp Population Estimates Using Automated Feature Extraction. 2020.

39. Lang, S.; Füreder, P.; Riedler, B.; Wendt, L.; Braun, A.; Tiede, D.; Schoepfer, E.; Zeil, P.; Spröhnle, K.; Kulessa, K.; et al. Earth Observation Tools and Services to Increase the Effectiveness of Humanitarian Assistance. Eur. J. Remote Sens. 2020, 53, 67-85, doi:10.1080/22797254.2019.1684208.

40. Quinn, J.A.; Nyhan, M.M.; Navarro, C.; Coluccia, D.; Bromley, L.; Luengo-Oroz, M. Humanitarian Applications of Machine Learning with Remote-Sensing Data: Review and Case Study in Refugee Settlement Mapping. Philos. Trans. R. Soc. Math. Phys. Eng. Sci. 2018, 376, 20170363, doi:10.1098/rsta.2017.0363.

41. Braun, A.; Fakhri, F.; Hochschild, V. Refugee Camp Monitoring and Environmental Change Assessment of Kutupalong, Bangladesh, Based on Radar Imagery of Sentinel-1 and ALOS-2. Remote Sens. 2019, 11, 2047, doi:10.3390/rs11172047. 
42. Aung, T.S.; Overland, I.; Vakulchuk, R.; Xie, Y. Using Satellite Data and Machine Learning to Study Conflict-Induced Environmental and Socioeconomic Destruction in Data-Poor Conflict Areas: The Case of the Rakhine Conflict. Environ. Res. Commun. 2021, 3, 025005, doi:10.1088/2515-7620/abedd9.

43. Jaafar, H.; Ahmad, F.; Holtmeier, L.; King-Okumu, C. Refugees, Water Balance, and Water Stress: Lessons Learned from Lebanon. Ambio 2020, 49, 1179-1193, doi:10.1007/s13280-019-01272-0.

44. Ahmed, B.; Rahman, M.S.; Sammonds, P.; Islam, R.; Uddin, K. Application of Geospatial Technologies in Developing a Dynamic Landslide Early Warning System in a Humanitarian Context: The Rohingya Refugee Crisis in Cox's Bazar, Bangladesh. Geomat. Nat. Hazards Risk 2020, 11, 446-468, doi:10.1080/19475705.2020.1730988.

45. Maystadt, J.-F.; Mueller, V.; Van Den Hoek, J.; van Weezel, S. Vegetation Changes Attributable to Refugees in Africa Coincide with Agricultural Deforestation. Environ. Res. Lett. 2020, 15, 044008, doi:10.1088/1748-9326/ab6d7c.

46. Friedrich, H.K.; Van Den Hoek, J. Breaking Ground: Automated Disturbance Detection with Landsat Time Series Captures Rapid Refugee Settlement Establishment and Growth in North Uganda. Comput. Environ. Urban Syst. 2020, 82, 101499, doi:10.1016/j.compenvurbsys.2020.101499.

47. Rossi, M.; Rembold, F.; Bolognesi, M.; Nori, M.; Mureithi, S.; Nyberg, G. Mapping Land Enclosures and Vegetation Cover Changes in the Surroundings of Kenya's Dadaab Refugee Camps with Very High Resolution Satellite Imagery. Land Degrad. Dev. 2019, 30, 253-265, doi:https://doi.org/10.1002/ldr.3212.

48. Alix-Garcia, J.; Walker, S.; Bartlett, A.; Onder, H.; Sanghi, A. Do Refugee Camps Help or Hurt Hosts? The Case of Kakuma, Kenya. J. Dev. Econ. 2018, 130, 66-83, doi:10.1016/j.jdeveco.2017.09.005.

49. Lüthje, F.; Tiede, D.; Füreder, P. Don't See the Dwellings for the Trees: Quantifying the Effect of Tree Growth on Multi-Temporal Dwelling Extraction in a Refugee Camp. GI_Forum 2015, 1, 406-415, doi:10.1553/giscience2015s406.

50. United Nations Division of Programme Support and Management Shelter Design Catalogue; UNHCR: Geneva, Switzerland, 2016;

51. Cole, G. Pluralising Geographies of Refuge. Prog. Hum. Geogr. 2021, 45, 88-110, doi:10.1177/0309132519900925.

52. Acolin, A.; Kim, A.M. Algorithmic Justice and Groundtruthing the Remote Mapping of Informal Settlements: The Example of Ho Chi Minh City's Periphery. Environ. Plan. B Urban Anal. City Sci. 2021, 2399808321998708, doi:10.1177/2399808321998708.

53. UNHCR UNHCR Global Trends 20182019.

54. Republic of Uganda UGANDA NATIONAL ACTION PLAN TO IMPLEMENT THE GLOBAL COMPACT ON REFUGEES AND ITS COMPREHENSIVE REFUGEE RESPONSE FRAMEWORK (CRRF) 2018.

55. UNHCR Uganda Country Refugee Response Plan: The Integrated Response Plan for Refugees from South Sudan, Burundi and the Democratic Republic of the Congo, January 2019 - December 2020 (Revised in March 2019) - Uganda 2019.

56. UNHCR Camp Planning Standards (Planned Settlements) Available online: https://emergency.unhcr.org/entry/45581/campplanning-standards-planned-settlements (accessed on 5 July 2021).

57. Esch, T.; Heldens, W.; Hirner, A.; Keil, M.; Marconcini, M.; Roth, A.; Zeidler, J.; Dech, S.; Strano, E. Breaking New Ground in Mapping Human Settlements from Space - The Global Urban Footprint. ISPRS J. Photogramm. Remote Sens. 2017, 134, 30-42, doi:10.1016/j.isprsjprs.2017.10.012.

58. Li, X.; Gong, P.; Zhou, Y.; Wang, J.; Bai, Y.; Chen, B.; Hu, T.; Xiao, Y.; Xu, B.; Yang, J.; et al. Mapping Global Urban Boundaries from the Global Artificial Impervious Area (GAIA) Data. Environ. Res. Lett. 2020, 15, 094044, doi:10.1088/1748-9326/ab9be3.

59. Yeboah, G.; Porto de Albuquerque, J.; Troilo, R.; Tregonning, G.; Perera, S.; Ahmed, S.A.K.S.; Ajisola, M.; Alam, O.; Aujla, N.; Azam, S.I.; et al. Analysis of OpenStreetMap Data Quality at Different Stages of a Participatory Mapping Process: Evidence from Slums in Africa and Asia. ISPRS Int. J. Geo-Inf. 2021, 10, 265, doi:10.3390/ijgi10040265.

60. Microsoft Microsoft Releases 18M Building Footprints in Uganda and Tanzania to Enable AI Assisted Mapping Available online: https://blogs.bing.com/maps/2019-09/microsoft-releases-18M-building-footprints-in-uganda-and-tanzania-to-enableai-assisted-mapping/ (accessed on 1 July 2021). 
61. OpenStreetMap WikiProject Uganda/Microsoft Building Imports for UBOS Pilot Census Preparation - OpenStreetMap Wiki Available online: https://wiki.openstreetmap.org/wiki/WikiProject_Uganda/Microsoft_building_imports_for_UBOS_pilot_census_preparation (accessed on 1 July 2021).

62. Schaefer, J.T. The Critical Success Index as an Indicator of Warning Skill. Weather Forecast. 1990, 5, 570-575.

63. Moore, B.; McKee, J.J. The Impact of Seasonality on Multi-Scale Feature Extraction Techniques. Int. J. Digit. Earth 2020, 13, 921, doi:10.1080/17538947.2018.1556354.

64. Sliuzas, R.; Kuffer, M.; Kemper, T. Assessing the Quality of Global Human Settlement Layer Products for Kampala, Uganda. In Proceedings of the 2017 Joint Urban Remote Sensing Event (JURSE); March 2017; pp. 1-4. 